\title{
Review of 10 years of practical RT-3DTEE (2010-2020)
}

\author{
Vu Tuan Nguyen* \\ *PNT Medical University HCMC, Medic HCMC Vietnam, Vietnam \\ *Corresponding author: Vu Tuan Nguyen, PNT Medical University HCMC, Medic HCMC Vietnam, Vietnam
}

\begin{abstract}
Objectives: Background: Real-time three dimensional transesophageal echocardiography or RT-3DTEE, with advances in image processing and display, has increased the availability and utility of TEE to a variety of clinical settings as diagnosis and catheter intervention.

Patients \& Methods: We study all Patients with RT-3DTEE, presented in MEDIC HCMC from October 2010 to May 2020.

Results: From October 2010 to May 2020, in MEDIC HCM, we have already performed 1276 cases ofReal-time 3DTEE: Mitral Stenosis (31\%), Atrial Septal Defects (16\%) and other diseases of the heart.The display of three dimensional images of 3DTEE providing important information's to assess the anatomical structures and the severity of diseases prior to perform interventional procedure.
\end{abstract}

Conclusion: Real-time 3DTEE overcomes the limitations of 2DTEE in making diagnosis and guiding the catheter intervention.

Keywords: Three Dimensional Transesophageal Echocardiography; Mitral Stenosis; Atrial Septal Defect

\section{Background}

The first utilization of a TEE device that promised to have clinical utility was reported in 1976 by Frazin and coworkers, who described the application of transesophageal M-mode echocardiography. The use of this technology was subsequently reported for the evaluation of ventricular function during supine exercise. The next success was the development of real-time, twodimensional TEE imaging, as first described in 1980 by Hisanaga, who developed a wide-angle mechanical sector scanner, while in 1982 Schluter reported on the use of transesophageal phased-array two-dimensional echocardiography. The incorporation of color mapping into a TEE device was first reported by investigators from Saitama Medical School in Japan. The same group was instrumental in early development of standard biplane, matrix phased -array biplane, and small pediatric probe. The current-generation probes are all multiplane devices. Rotating the small control wheel flexes, the tip to the left or to the right. But with the multiplane TEE transducer, this manipulation is rarely necessary. Rotation of the transducer refers to movement of the sector scan from 0 to
180 degrees. Transthoracic and transesophageal real-time three dimensional echocardiography is a significant advancement in technology. Advances in image processing and display, the addition of three dimensional imaging capability, and the portability of ultrasound system have increased the availability and utility of TEE to a variety of clinical settings as diagnosis, cardiac catheterization, operation and intensive care. Currently percutaneous interventions for many structural diseases increase more and more in our country. Interventional cardiologists are now treating a variety of lesions that previously required surgery as mitral stenosis, aortic stenosis, ostium secundum ASD, VSD, PDA, Coronary Fistula... Although Fluoroscopy and 2D TEE are usually used for procedural guidance, real-time three-dimensional TEE offers several important advantages over these modalities. Previously, Toshiba SSH $140 \mathrm{~A}$ with TEE biplan probe have been used to perform 2D TEE in our hospital. Since October 2010, transesophageal echocardiographies are made by X-MATRIX, iE 33 Philips machine. 


\section{Endpoints of study}

i. Role of 3DTEE in the assessment of heart diseases.

ii. Advantages of 3DTEE in compare with 2DTEE.

\section{Patients and Methods}

a) Pts with 3D TEE at MEDIC HCM, Viet Nam, from October 2010 to May 2020.

Instruments: X-MATRIX Philips iE33, X-7 real-time 3D TEE probe.

Acquision mode including Live 3D or narrow sector, Full Volume or wide sector, Zoom or the smallest pyramydal size available for acquisition.

\section{Techniques}

i. Explain the procedure to the patient.

ii. The patient should not have had any intake of food or drink for at least 4-6 hours.

iii. Oral prostheses should be removed.

iv. The patient should be placed in the left lateral decubitus position. v. Topical anesthetic and sedation.

vi. Introduce a bite block between the teeth.

vii. The probe is gently passed into the oral cavity over the tongue and guided into the larynx.

viii. The patient should be asked to swallow, the probe is gently introduced into esophagus.

b) Case series report study is applied for this topic.

c) The advantages of 3DTEE in compare with 2DTEE in diagnosis and evaluation of diseases prior to perform interventions.

\section{Results}

From October 2010 to May 2020, in MEDIC HCMC, we have already performed 1278 cases of 3DTEE: Mitral stenosis (31\%) and other valvulopathie including Mitral Regurgitation, Aortic valvopathies, Atral Septal Defects (16\%) and other shunts as PDA, VSD; then Myxoma and cardiac tumors, Endocarditis, studying prosthetic valves. The other complicated cardiopathies as Coronary artery fistula, Valsalva sinus rupture, Ebstein anomaly. The percutaneous balloon mitral valvuloplasty, transcatheter closure of ASD and surgery have demonstrated the precised diagnosis of 3DTEE (Figure 1).

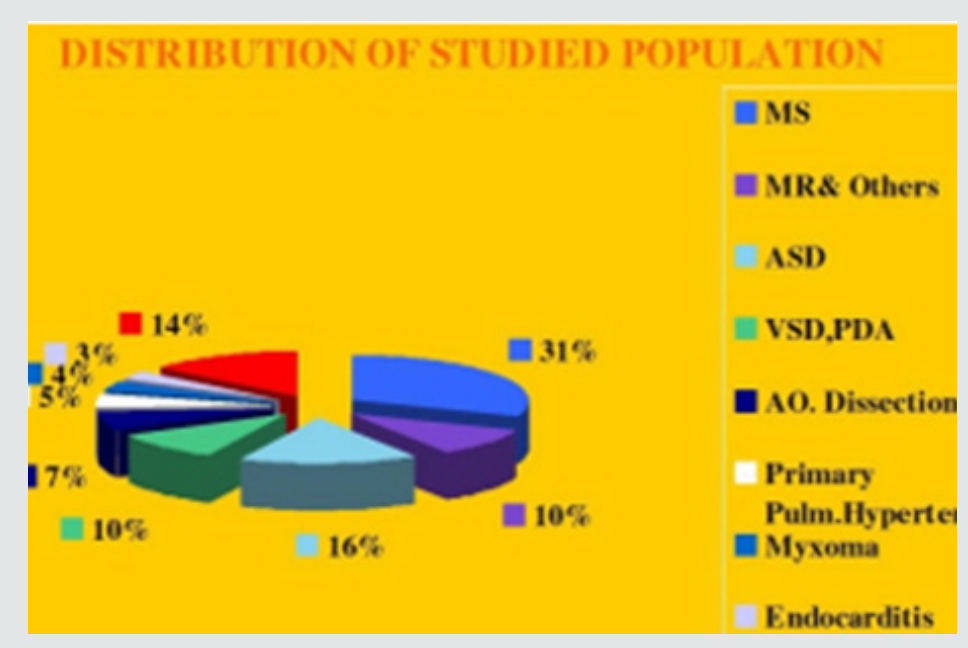

Figure 1: Distribution of heart diseases detected by RT-3DTEE.

Among 396 Pts with MS, mean age=45 (from 18-72 ages), the majority of patients were female $(75,2 \%)$, Dyspnea is the first symptom to the consultation, sometime embolic events $(7.5 \%)$ keep patients going to their cosultants, $\mathrm{AF}$ account $6,1 \%$. Rheumatic Fever is predominant cause, with important fusion of commissures (70\%), 2DTEE completed by 3DTEE is used to calculate the Wilkins score, providing information's more exactly than 2D TTE alone, prior to perform Balloon Mitral Commissurotomy or surgery. MVA ${ }^{3 D}$ measured by Real-Time 3DTEE to compare with conventional two-dimensional planimetry $\mathrm{MVA}^{2 \mathrm{D}}$.The 3D Assessment was significantly smaller the 2D planimetry: $\mathrm{MVA}^{3 \mathrm{D}}=0.95 \mathrm{~cm}^{2} \pm 0.21$; $\mathrm{MVA}^{2 \mathrm{D}}=1.16 \mathrm{~cm}^{2} \pm 0.24$; mean difference $=-0.21 \mathrm{~cm}^{2}, \mathrm{n}=327, \mathrm{p}<0,001$. Some patients with high Wilkins score evaluated by 2DTEE still have responded well to Balloon Mitral Valvuloplasty. Real-time three dimensional transesophageal echocardiography provides important information's regarding the involvement of rheumatic process on the mitral valve, particularly the symmetry length of commissural fusion. Furthermore RT-3DTEE also shows the thickening, the fibrosis and the calcification of the whole mitral commissures that cannot be visualized by 2DTEE. The 3D image 
allows superior visualization of the thickening of the mitral leaflet, particularly the commissures. The 3DTEE usually details the sub valvular apparatus not appreciated on 2DTEE while studying the leaflets. Because patients often presented late in Hospitals, their Wilkins score usually is high (68\% with Wilkins score is superior to 8). Especially, LAA thrombus, even small size, furthermore, can be detected more clearly on RT- 3DTEE. Volume and mobility of LAA thrombus appreciated better on 3DTEE. Detection LA and LAA thrombus by RT-3DTEE is more sensitive than 2DTEE with X-plane mode and 3 D Zoom only are available in 3DTEE. Direct planimetry of mitral valve orifice by 3DTEE is the gold standard method now. The cropping function ensures that the orifice area is traced in a plan that is at the tip of the mitral valve (Figure 2-17).

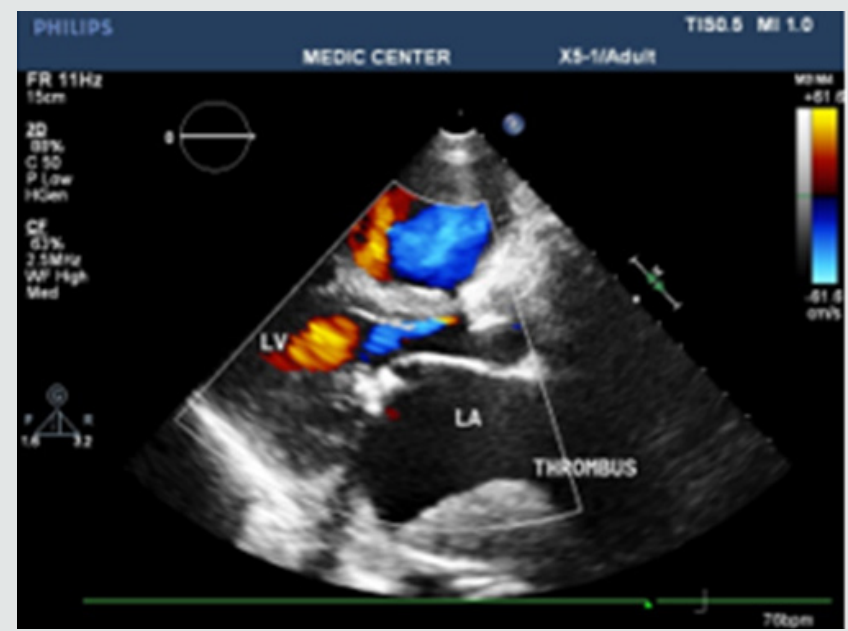

Figure 2: LAX view showing MS with severely calcified mitral leaflets\& presence of LA thrombus.

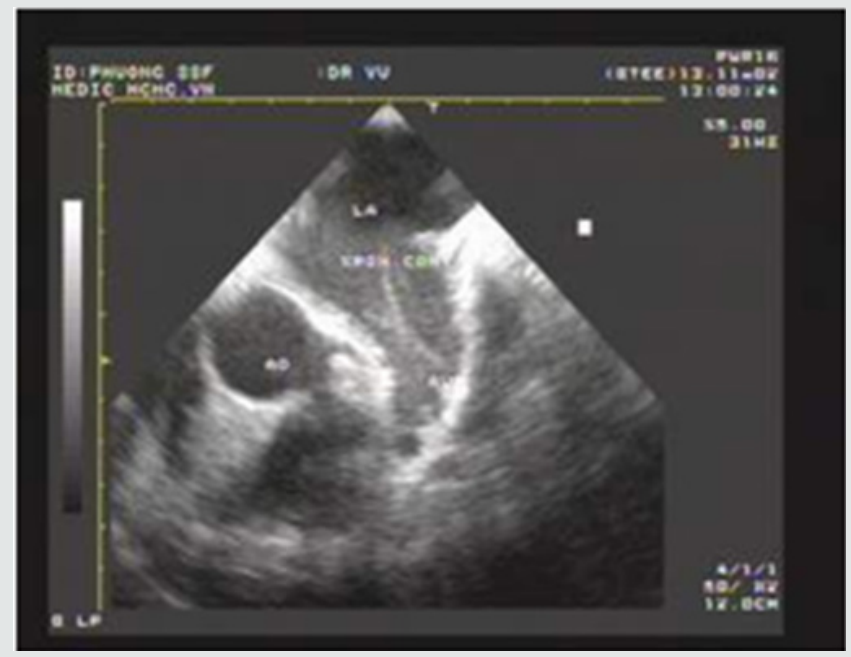

Figure 3: Spontaneous contrast in LAA recorded from 2DTEE.

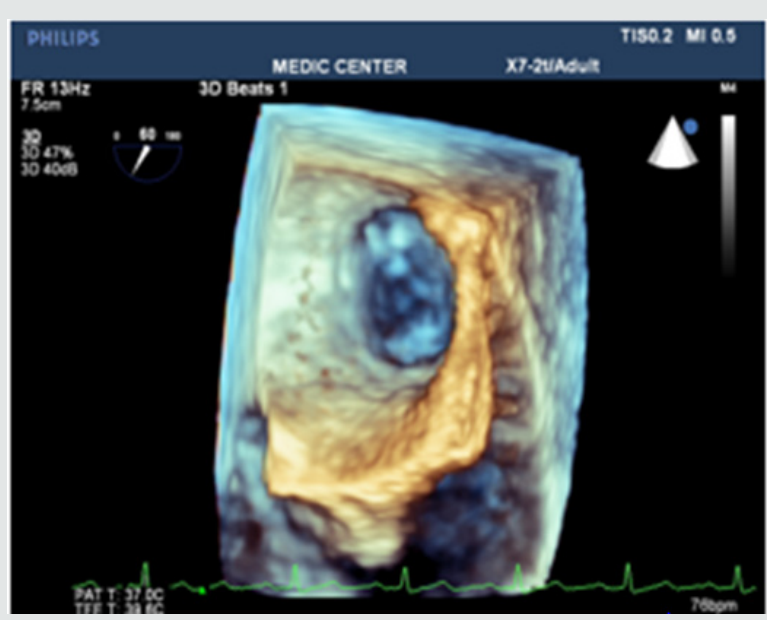

Figure 4: Normal LAA without thrombus inside, visualized by 3D Zoom.

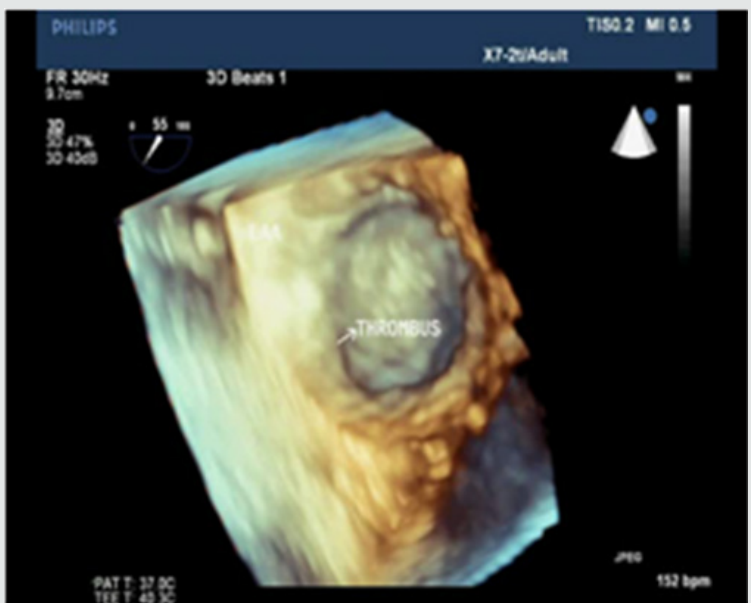

Figure 5: 3D Zoom imaging demonstrating LAA with thrombus inside.

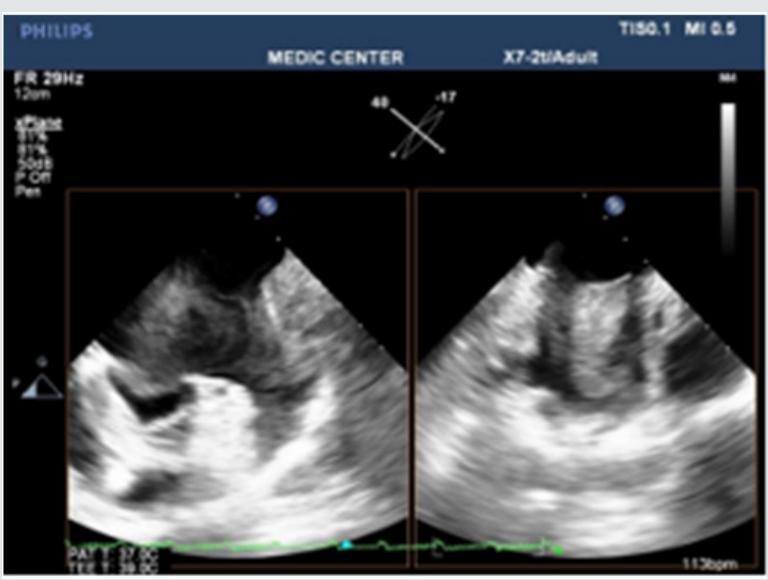

Figure 6: X-plane imaging visualizes LAA thrombus in two orthogonal planes. 


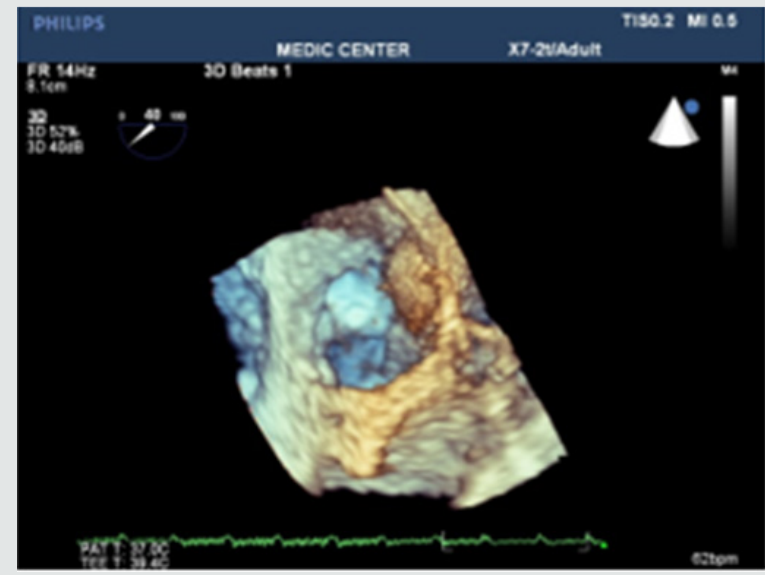

Figure 7: LAA three dimensional view with thrombus attached to LAA wall.

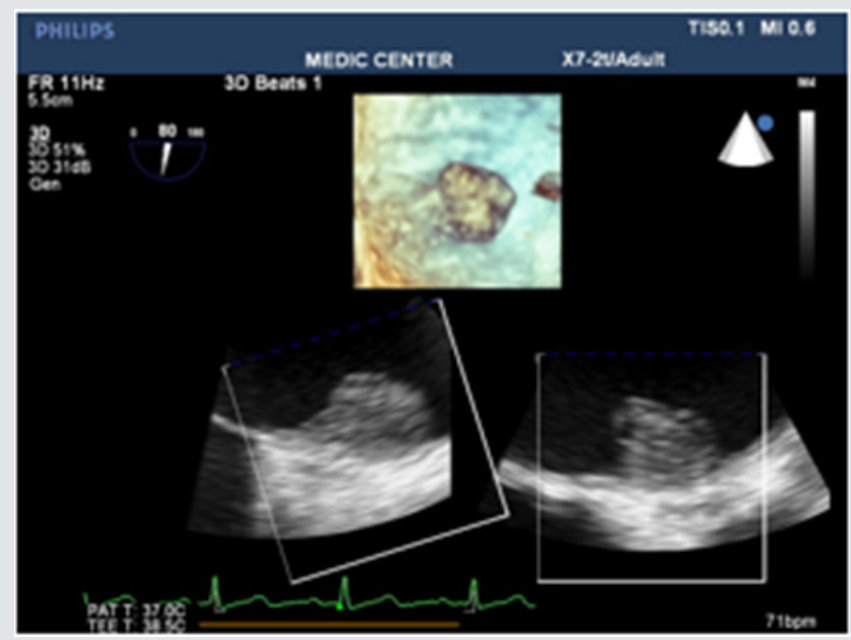

Figure 8: 3DTEE with in crop function shows thrombus attached to LA wall.

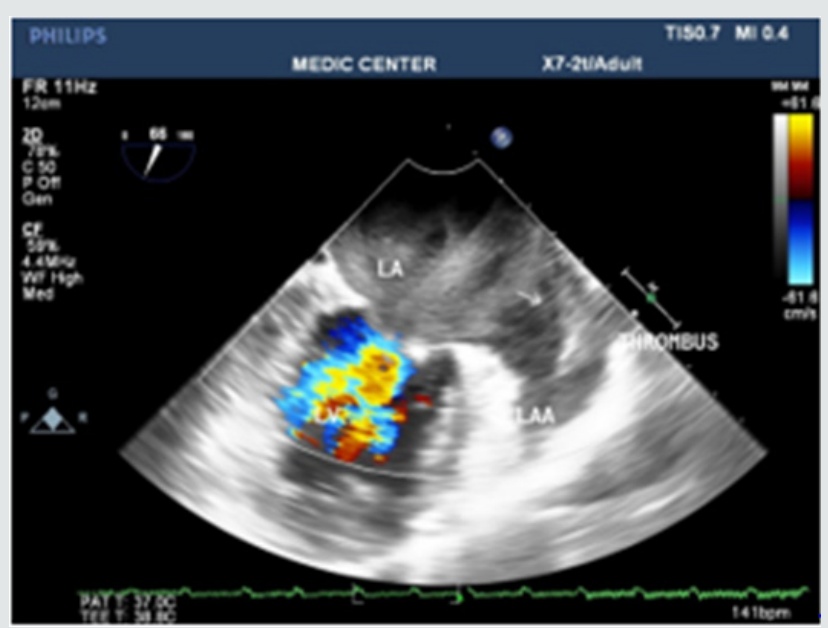

Figure 9: MS with spontaneous contrast and thrombus in LA\& LAA, 2DTEE plane of $60^{\circ}$

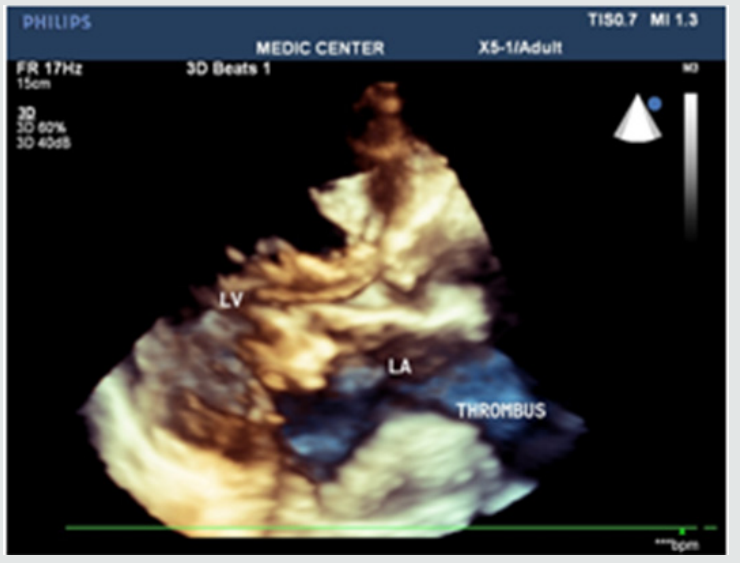

Figure 10: 2DTTE parasternal LAX view shows the doming appearance of AML,thickening of subvalvular apparatus, thrombus in LA.

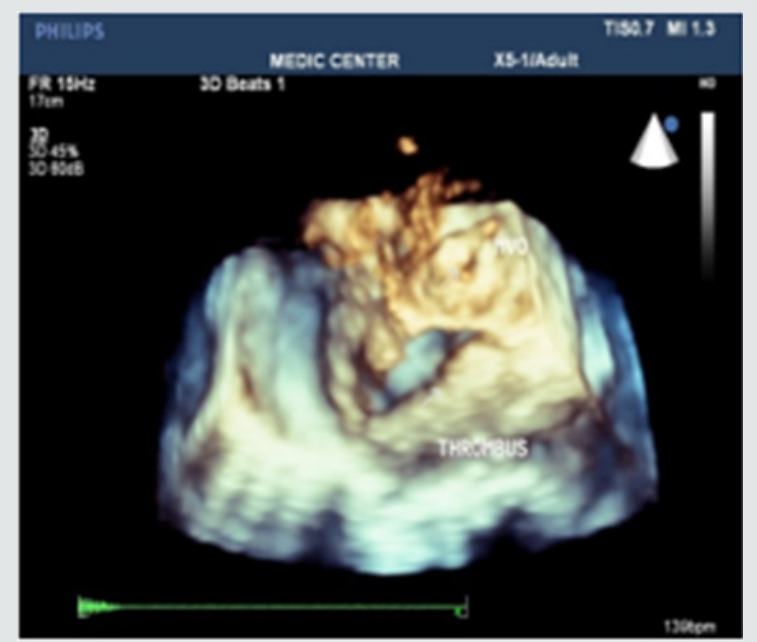

Figure 11:3DTTE Full volume demonstrating the restricted orifice with commissural fusion and LA thrombus.

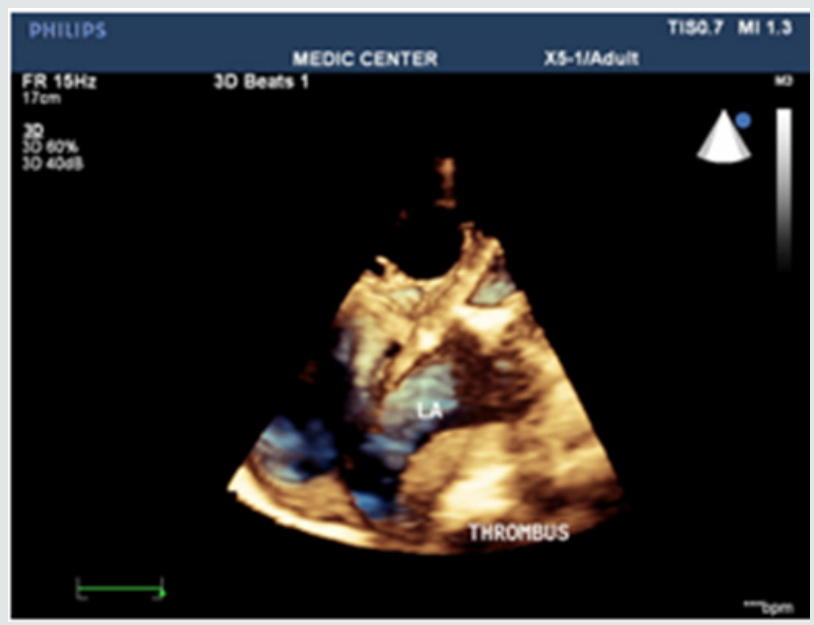

Figure 12: 2DTTE $4 \mathrm{C}$ view shows the $3 \mathrm{D}$ image of thrombus in LA. 


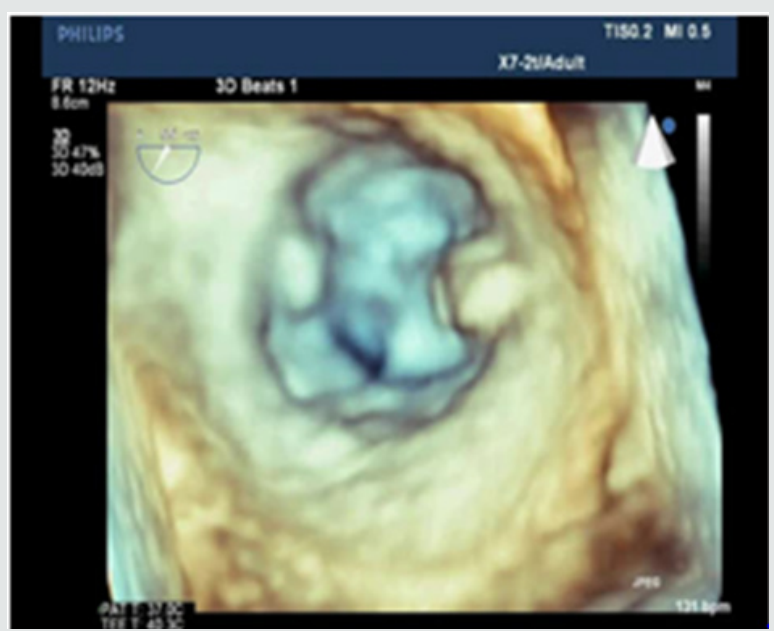

Figure 13: RT-3DTEE shows small and restricted mitral orifice, commissural fusion, extensive rheumatic nodules, severe deformity of mitral leaflets.

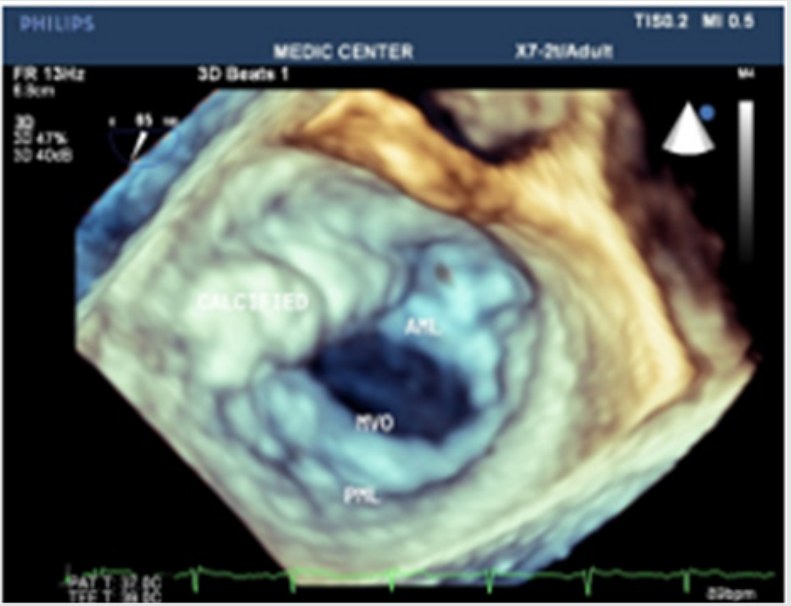

Figure 14: Zoom 3DTEE image visualizing the thickened leaflets, commissural fusion, nodules of rheumatic fever.

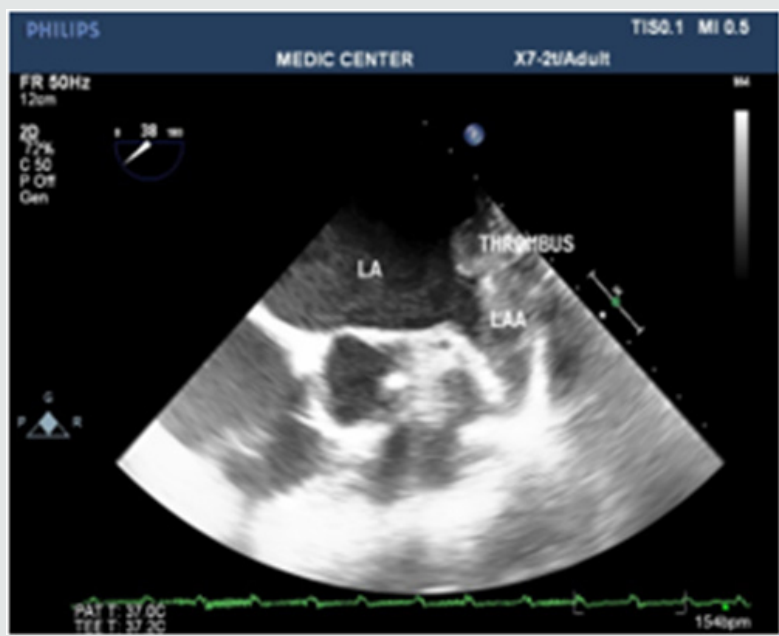

Figure 15: 2DTEE presenting LAA thrombus

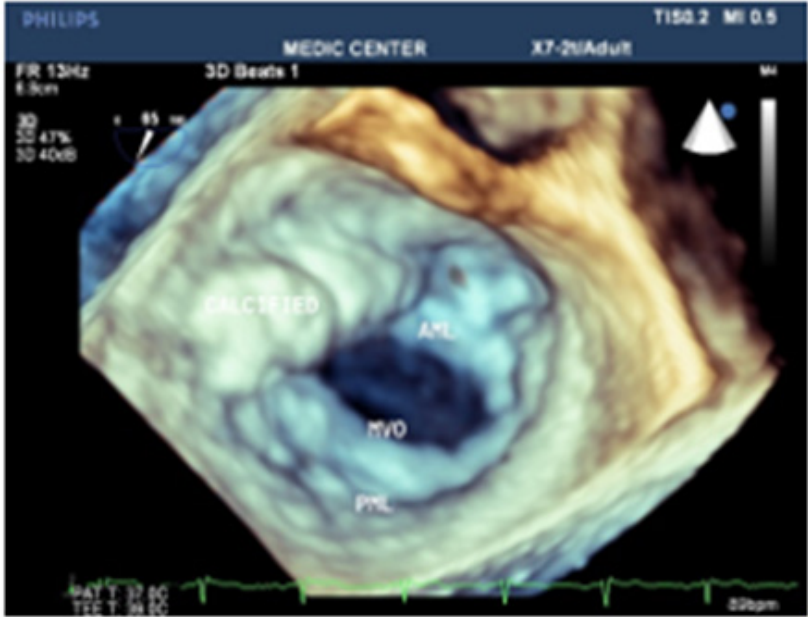

Figure 16: Zoom 3DTEE showing MS with comissural fusion and rheumatic nodules.

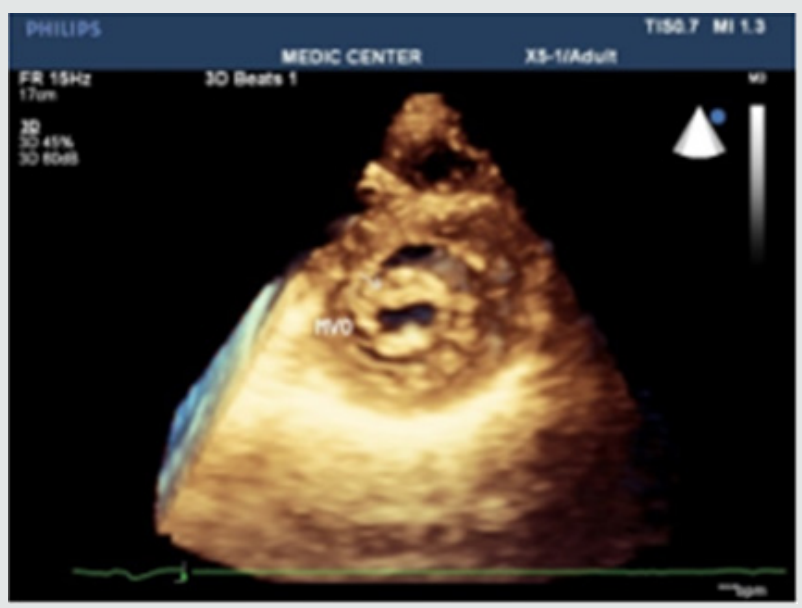

Figure 17: Parasternal 3D TTE demonstrating fusion of commissures and rheumatic nodules.

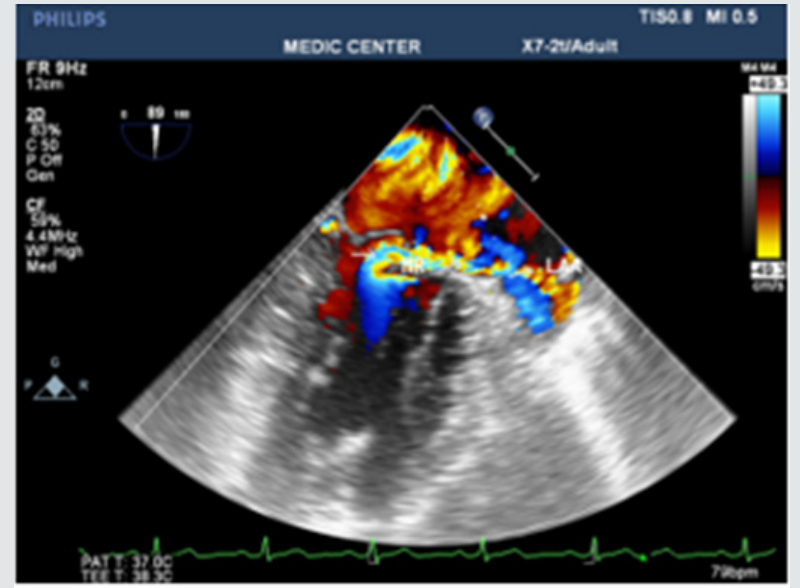

Figure 18: 2DTEE 90 plane visualizes a severe MR with excentric jet radiating into LAA. 
Among patients with mitral regurgitation, MVP accounts for most of our patients, fibroelastic disease and Barlow type of MVP were seen (Figure 18-21).

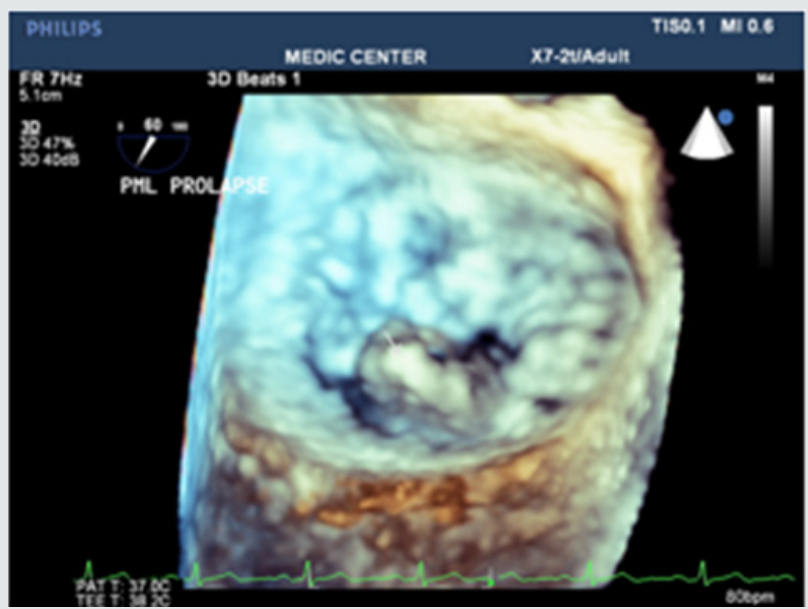

Figure 19: RT-3DTEE notes protruding PML viewed from LA side.

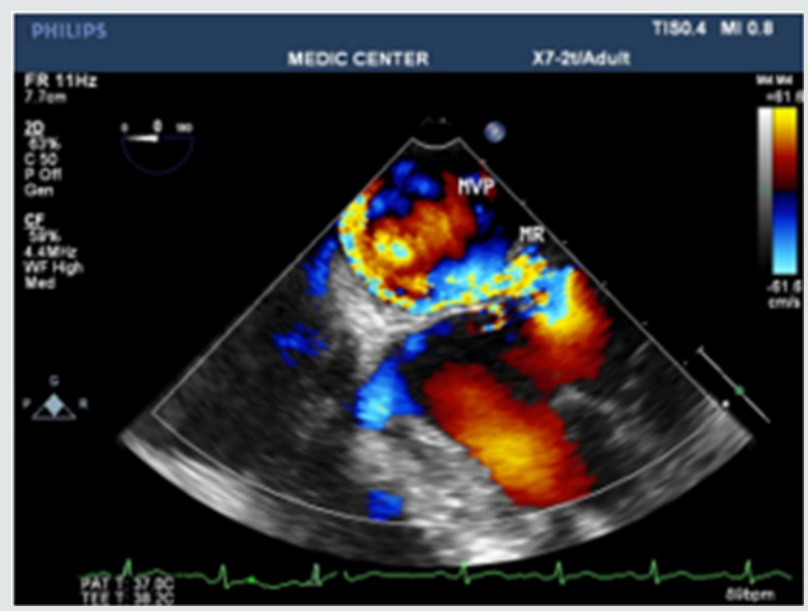

Figure 20: Excentric jet MR due to Flail MV

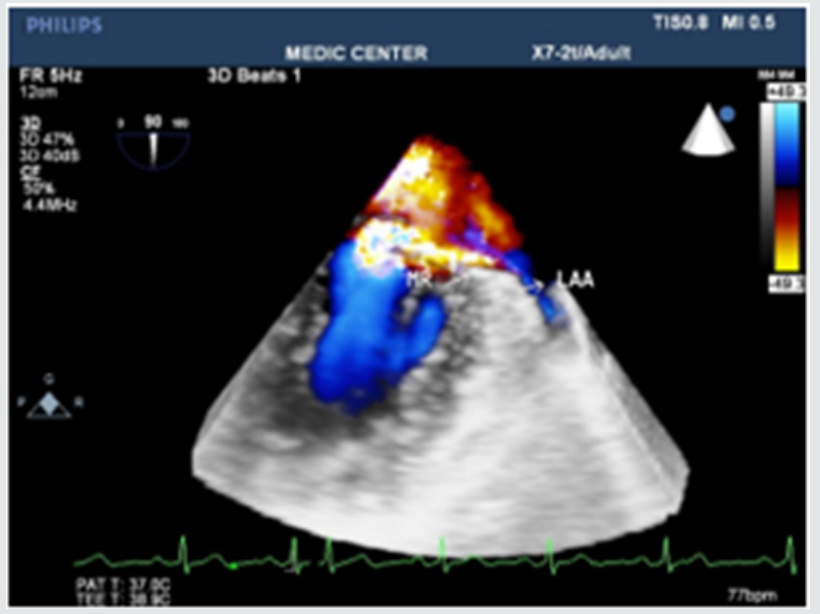

Figure 21: Live 3D shows the severe MR
Among 204 Pts with ASD, the secundum defects account for approximately 78\%, then primum ASDs 6\%, sinus venosus ASDs $12 \%$, multiple shunt ASD 4\%, unroofed coronary sinus not seen. 3D TEE can assess the size of ASD and the circumferential rims to select Patients for Transcatheter closure. Currently we perform ASD closure limited to ASDs less than $30 \mathrm{~mm}$ and with at least $5 \mathrm{~mm}$ of circumferential rims (Table 1 ).

Table 1.

\begin{tabular}{|c|c|c|c|c|}
\hline ASD & Ostium II & Ostium I & $\begin{array}{c}\text { Sinus } \\
\text { Venosus }\end{array}$ & Multiple Shunt ASD \\
\hline 217 & 170 & 13 & 26 & 8 \\
\hline
\end{tabular}

The X-plan mode can be used to estimate the maximal diameter of defect in two orthogonal planes. Three dimensional (3D) TEE imaging is an important adjunct to 2D imaging because multiplanar reconstruction ensures that the defect is measured accurately. Three dimensional (3D) TEE images can be rotated to demonstrate the defect from the RA or LA side in evaluating the secundum atrial septal defect rims. This improves understanding of their shape and relationships to surrounding intracardiac structures. Multiple ASDs account only 4\%, 3D TEE with wide sector can detect and visualize all the shunts through IAS (Figure 21-37).

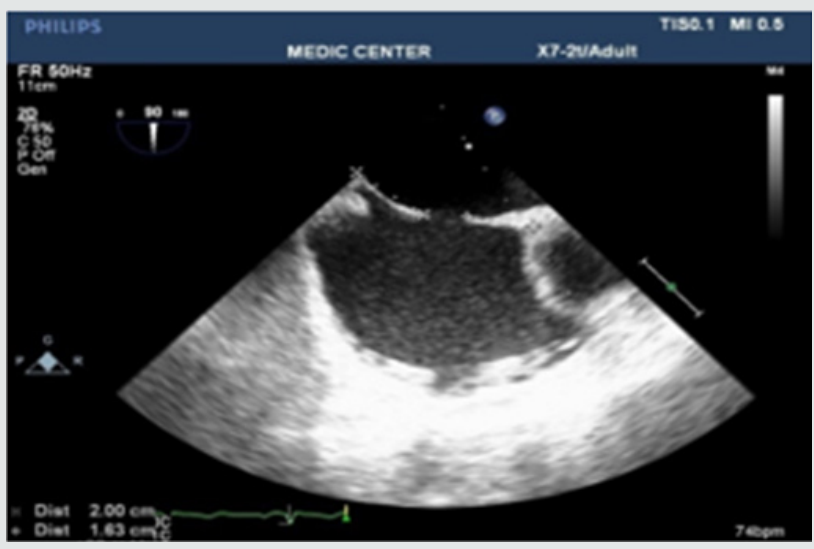

Figure 22: 2DTEE multiplane at $90^{\circ}$ (Bicaval view) visualizing a secundum ASD.

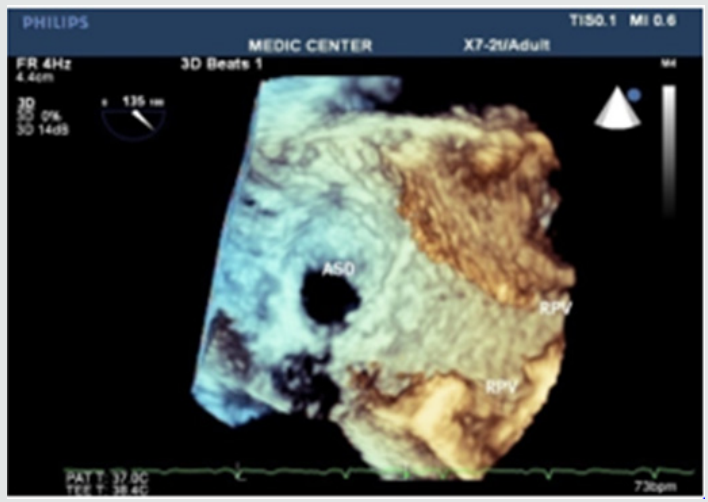

Figure 23: 3DTEE Zoom mode presenting a secundum ASD (shape, size, all rims). 


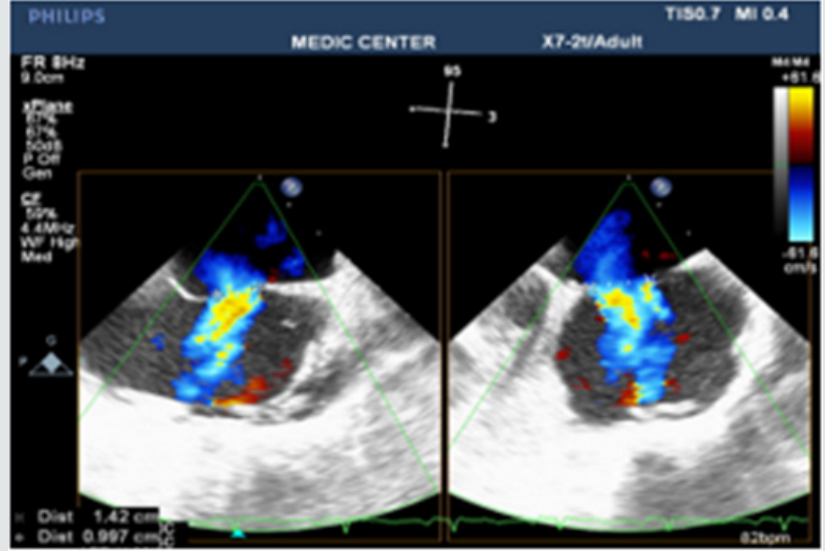

Figure 24: 2DTEE X-plane showing the L-R shunting through the secumdum ASD

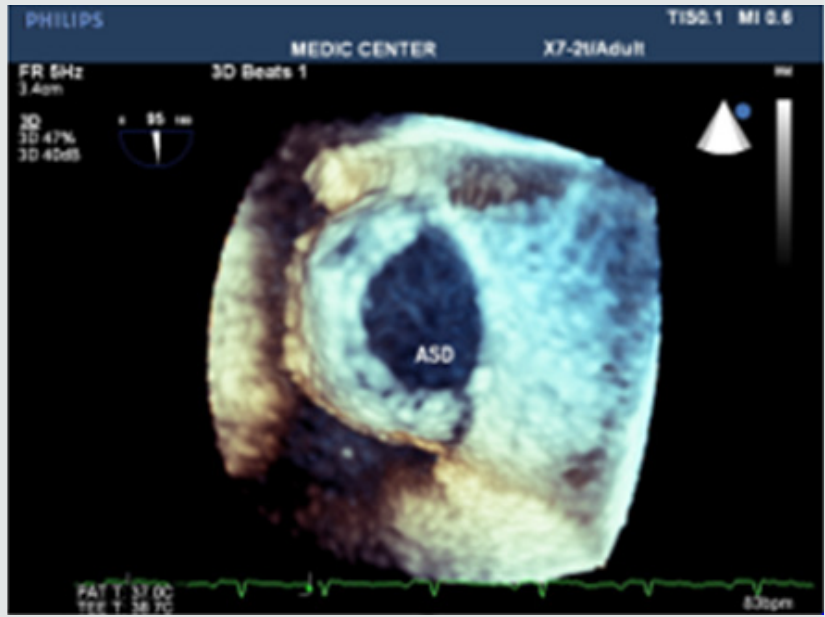

Figure 25: 3D image better demonstrates the shape and size of the secundum ASD.

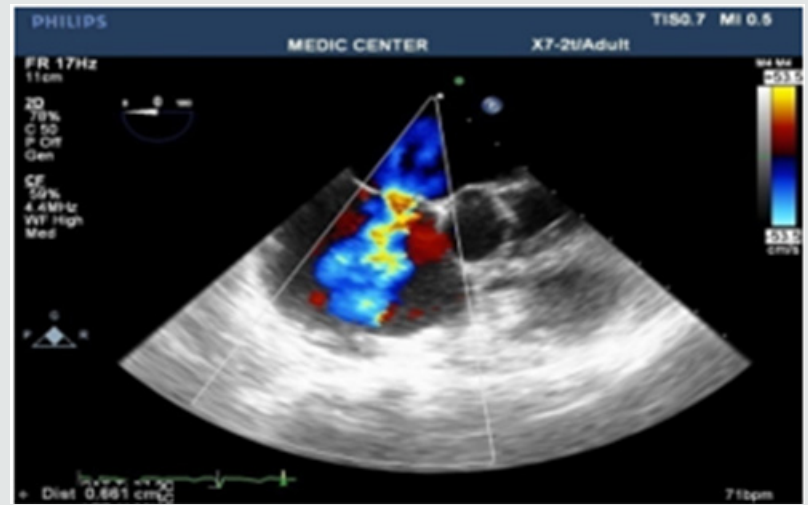

Figure 26: L-R shunting secundum ASD demonstrated with color flow imaging.

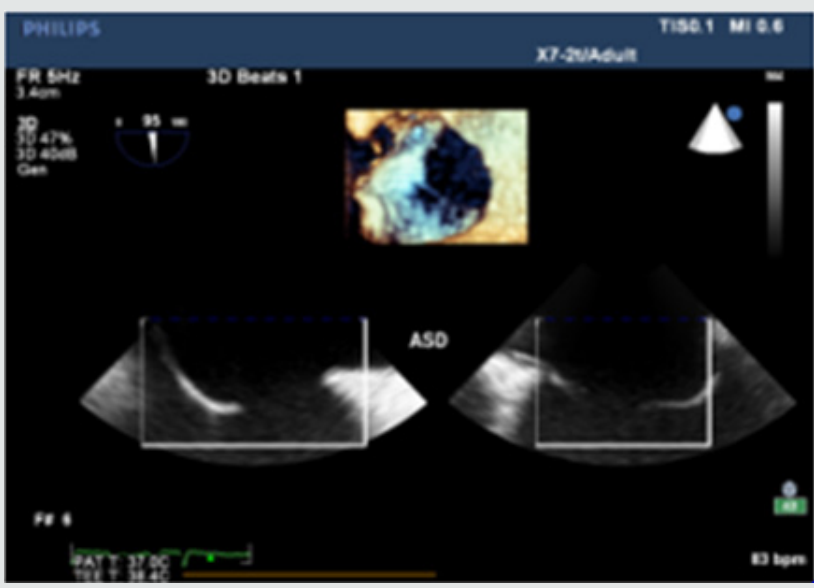

Figure 27: crop mode showing simultaneously 3D and 2D images.

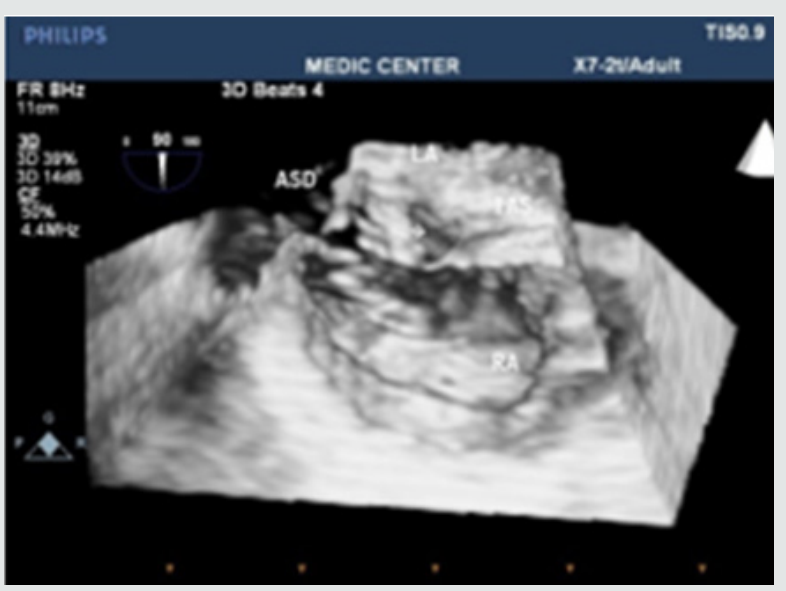

Figure 28: Multibeats live mode without color flow imaging visualizes a secundum ASD.

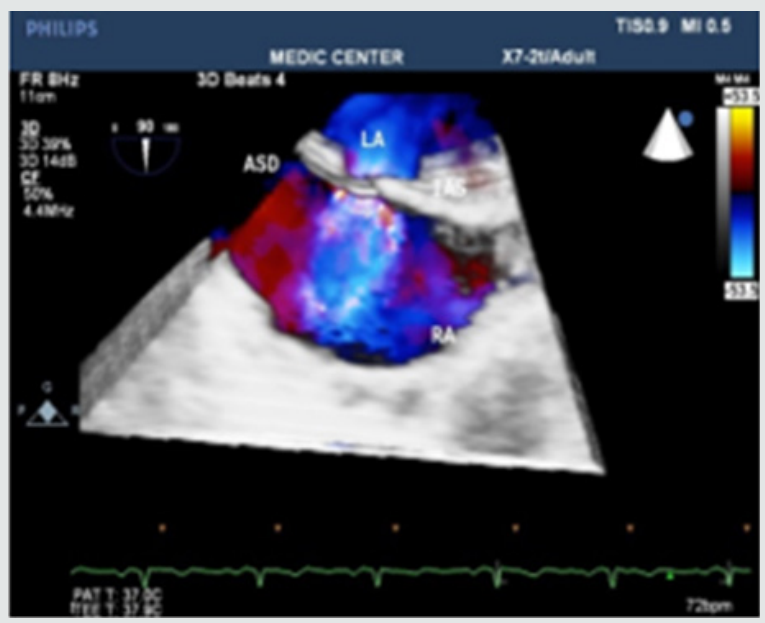

Figure 29: Multibeats live mode with color fow mapping visualizes the L-R shunt. 


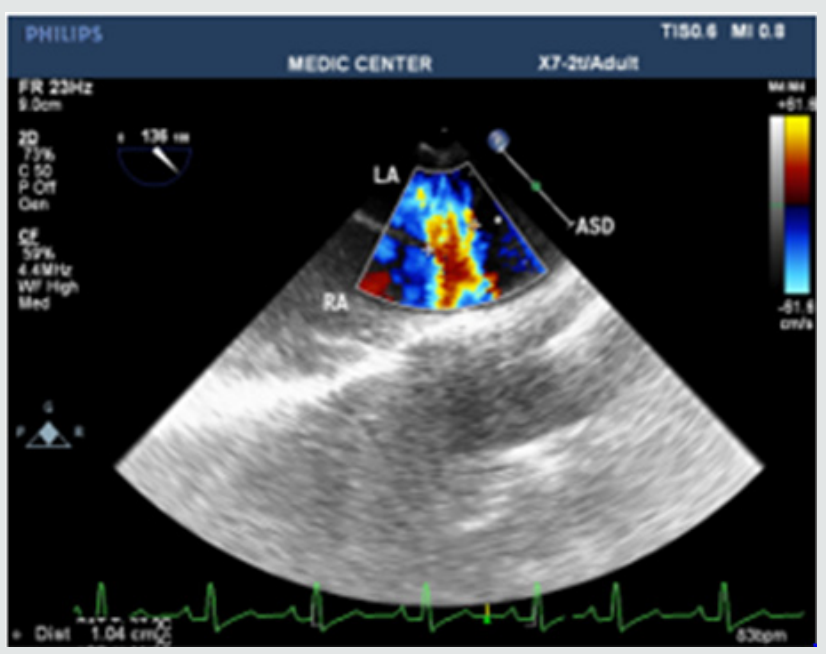

Figure 30: SVC sinus venosus ASD with L-R shunting.

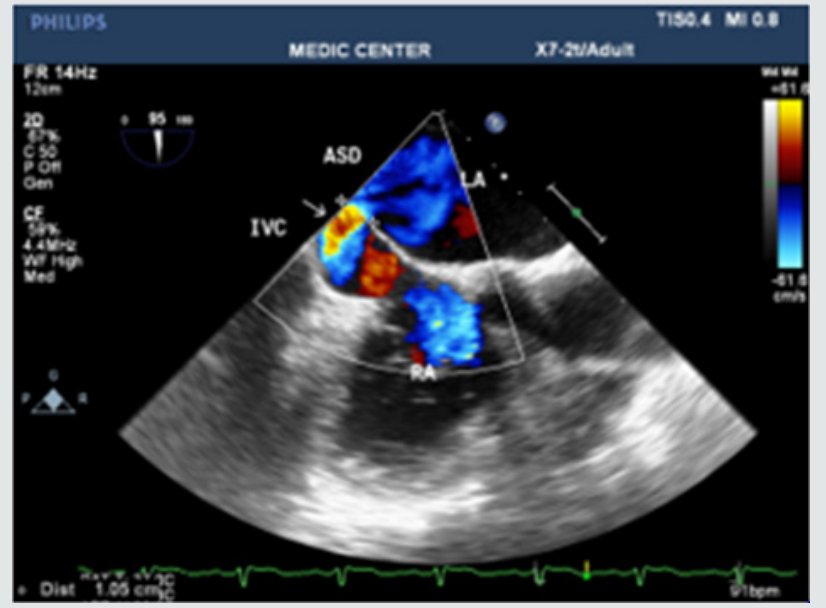

Figure 31: IVC sinus venosus ASD with L-R shunting.

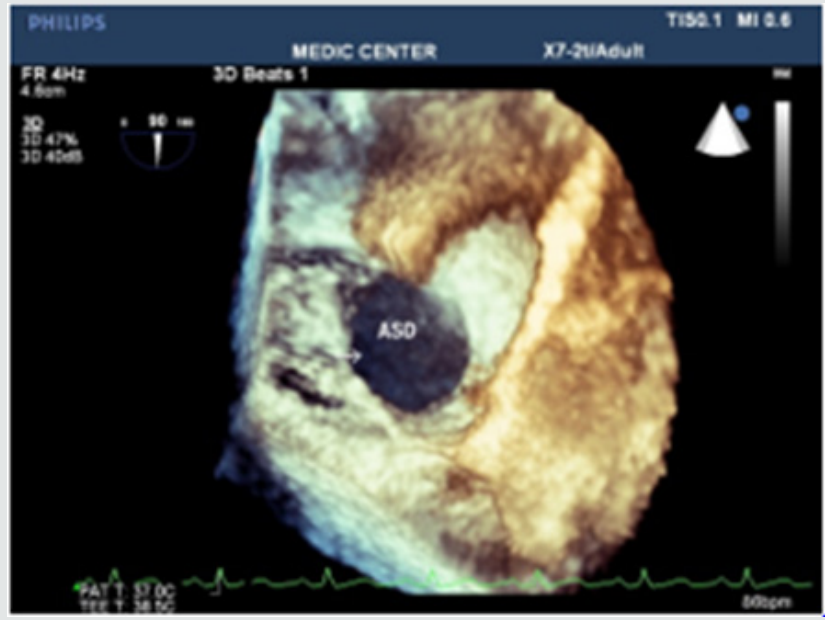

Figure 32: Secundum ASD viewed from LA

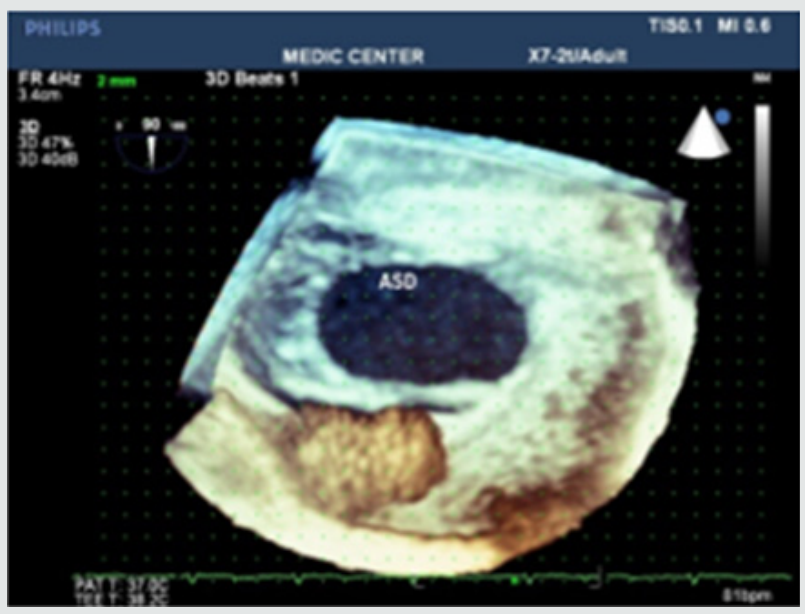

Figure 33: Secundum ASD visualized on 3DTEE Zoom mode.

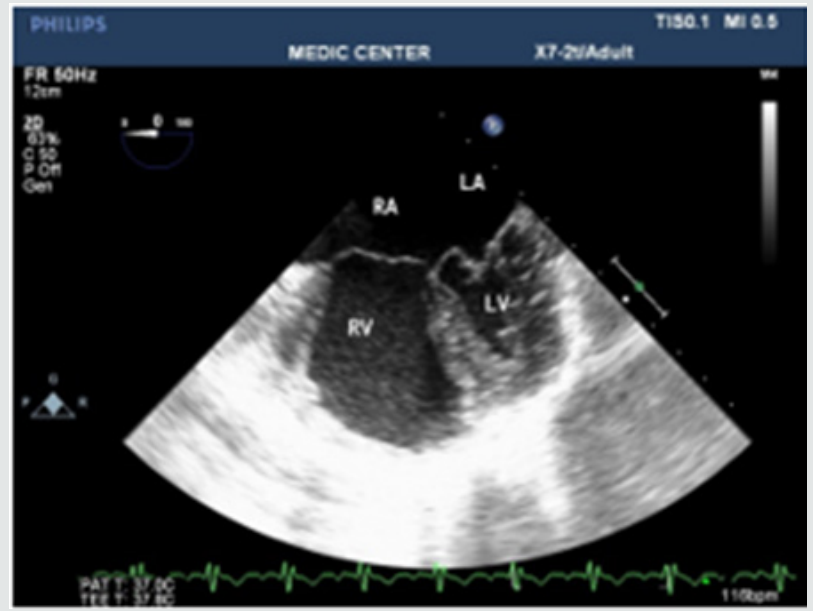

Figure 34: Primum ASD viewed on 2DTEE

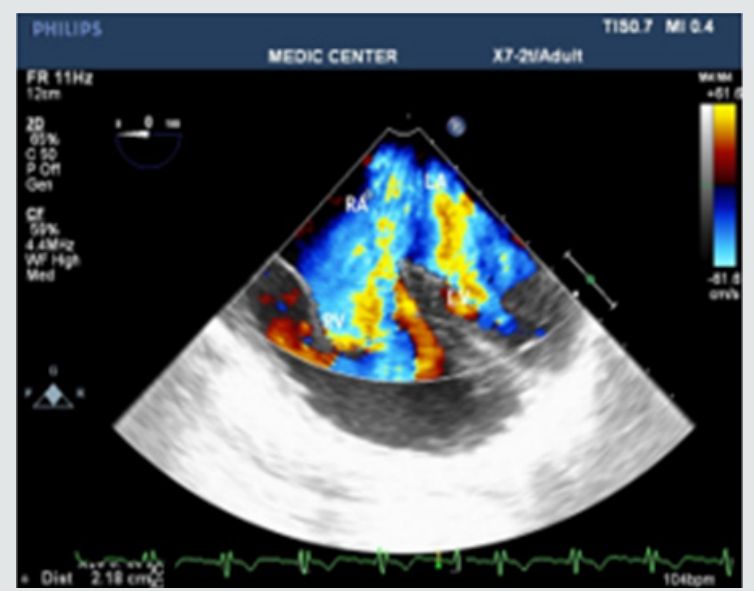

Figure 35: Multiplane 2DTEE with color shows the papillon sign of defect 


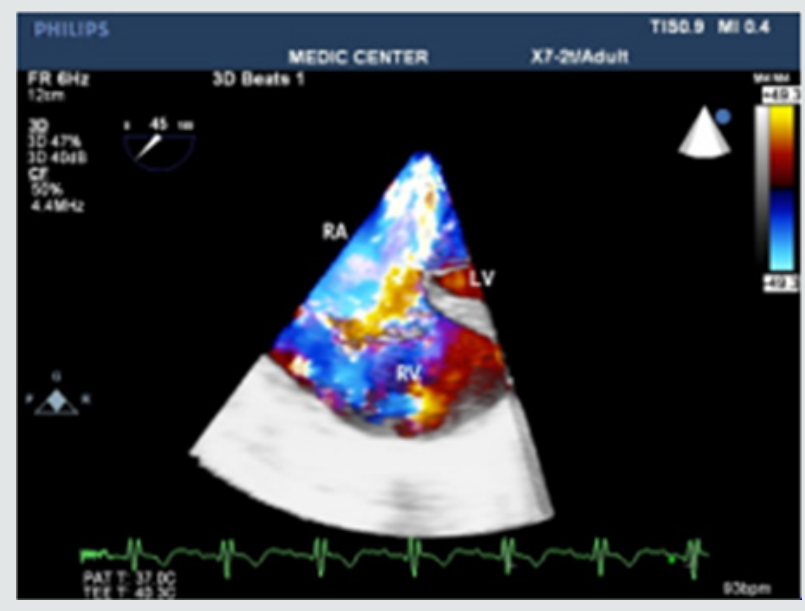

Figure 36: Primum ASD with L-R shunting seen on Live 3DTEE.

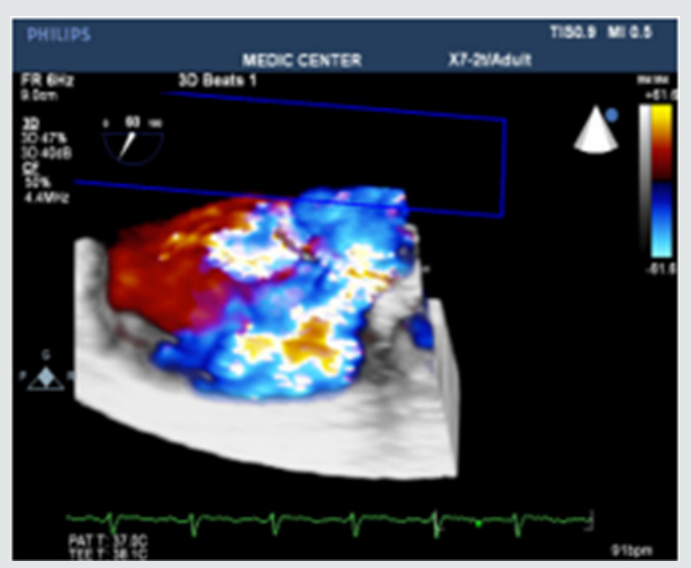

Figure 37: Multiple ASD visualized from Live 3DTEE

Cardiac myxomas in our study develop in the LA, pedunculated and attached to IAS. Three dimensional (3D) TEE shows the location, the size, the mobility and the stalk of myxoma on Live 3D and Full volume. Narrowing the diagnosis down by 2DTEE and then 3DTEE should be and is the target of echocardiographic imaging. Three dimensional 3DTEE can study the obstruction of mitral orifice caused by protruding myxoma [1-17].

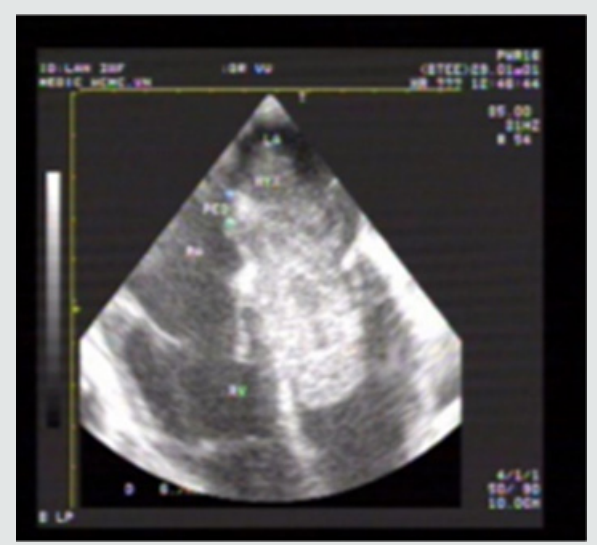

Figure 38: Giant myxoma seen on 2DTEE
Tumor of the RV and Fibroblastoma of aortic cups were noted in our study (Figure 38-43).

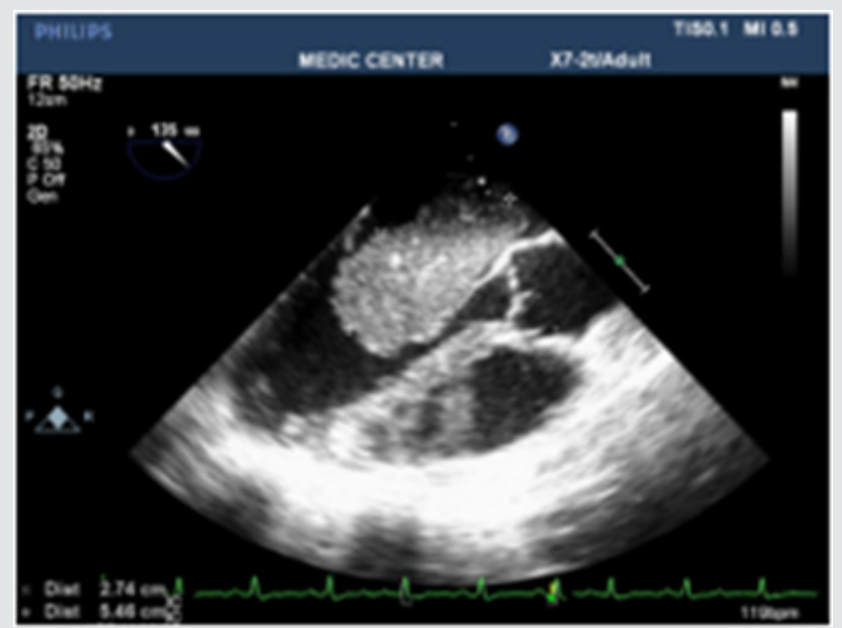

Figure 39: 2DTEE multiplane at $135^{\circ}$ shows LA myxoma.

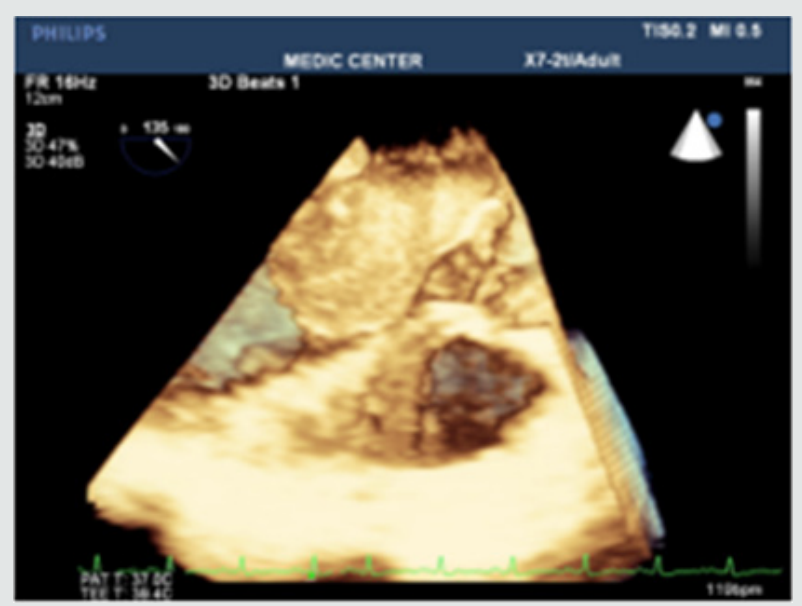

Figure 40: LA myxoma visualized on 3DTEE Live mode.

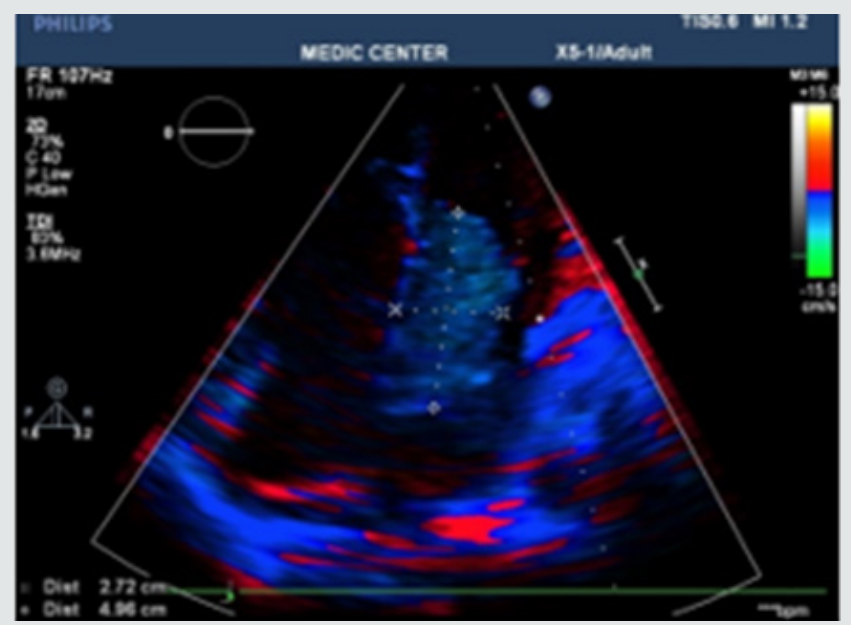

Figure 41: LA myxoma viewed on 2D TTE TDI. 


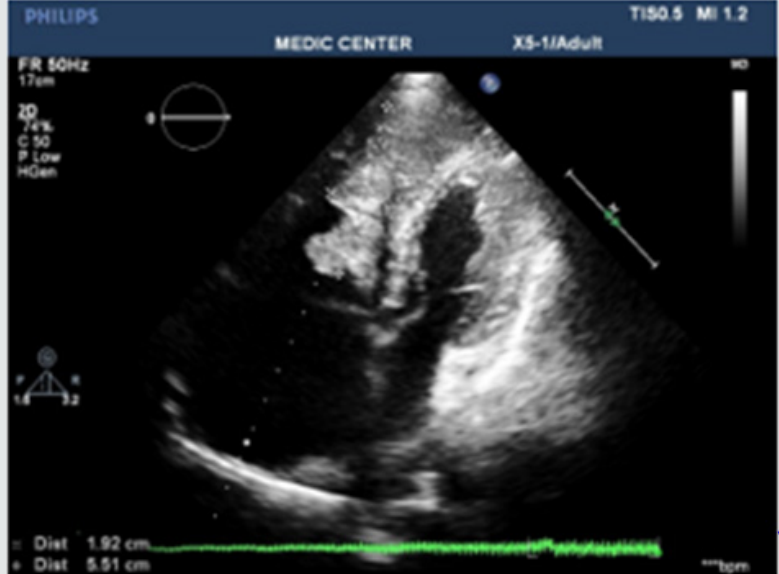

Figure 42: extensive tumor of RV detected on 2DTTE

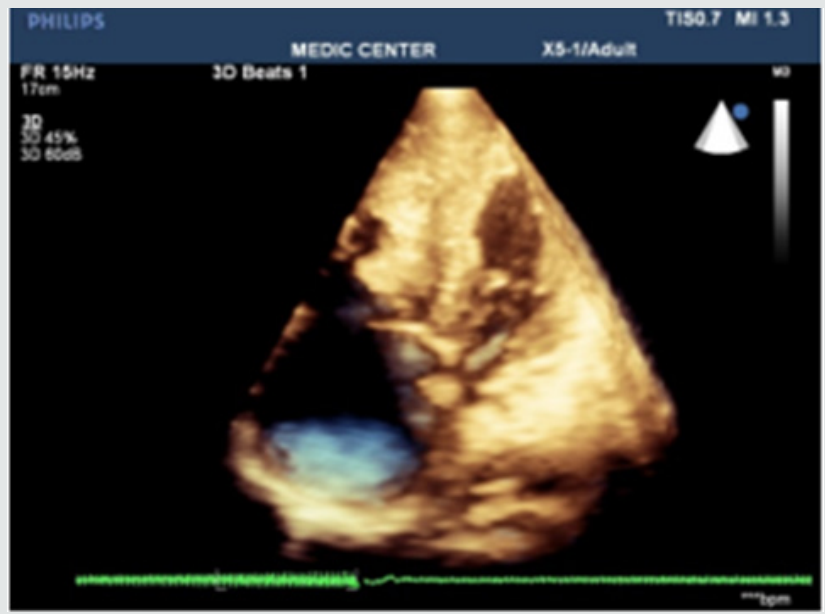

Figure 43: RV tumor viewed from 3DTTE

Endocarditis, infection of the endocardium and heart valves, the diagnosis and therapeutic of this condition has improved by echocardiography, especially TEE. Echocardiography not only provides evidence of endocardial infection as vegetation, but also offers important hemodynamic information like regurgitation severity and other structural complications. The vegetations in our study have been found on the mitral leaflets with MVP, bicuspid aortic cusps, pulmonary valves and beside small VSD. Among 12 cases of Infective Endocarditis, the underlying cardiac lesions includes MVP, Bicuspid Aorta, VSD and pulmonic valve stenosis (Table 2) (Figure 44-52).

Table 2.

\begin{tabular}{|c|c|c|c|c|}
\hline $\begin{array}{c}\text { Underlying } \\
\text { Diseases }\end{array}$ & $\begin{array}{c}\text { MVP, Rheumatic } \\
\text { MR }\end{array}$ & $\begin{array}{c}\text { Bicuspid } \\
\text { Aorta }\end{array}$ & VSD & $\begin{array}{c}\text { Pulmonic } \\
\text { Stenosis }\end{array}$ \\
\hline 12 & 5 & 3 & 3 & 1 \\
\hline
\end{tabular}

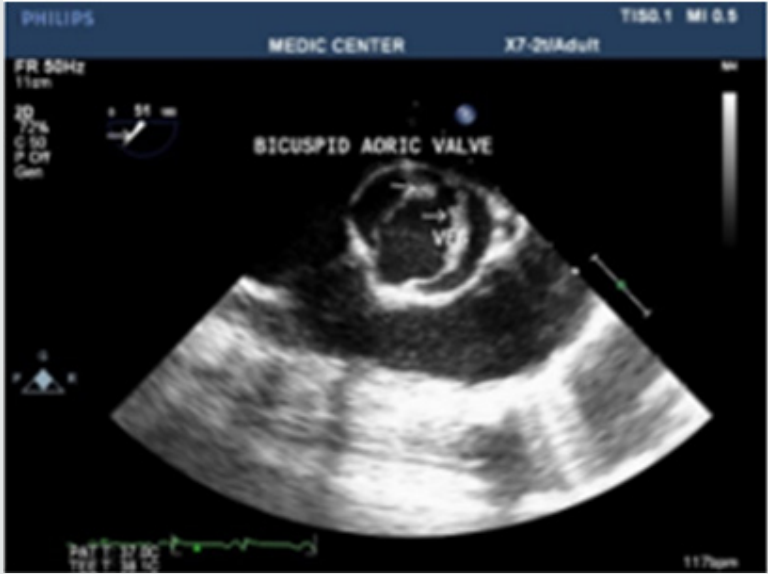

Figure 44: Bicuspid Aorta with vegetation seen on 2DTEE

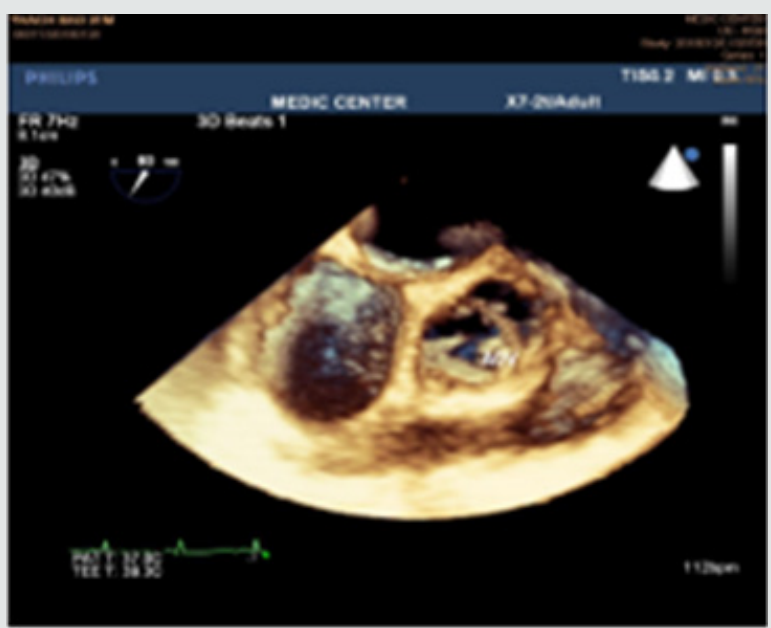

Figure 45: Bicuspid Aorta with vegetation seen on Live 3DTEE

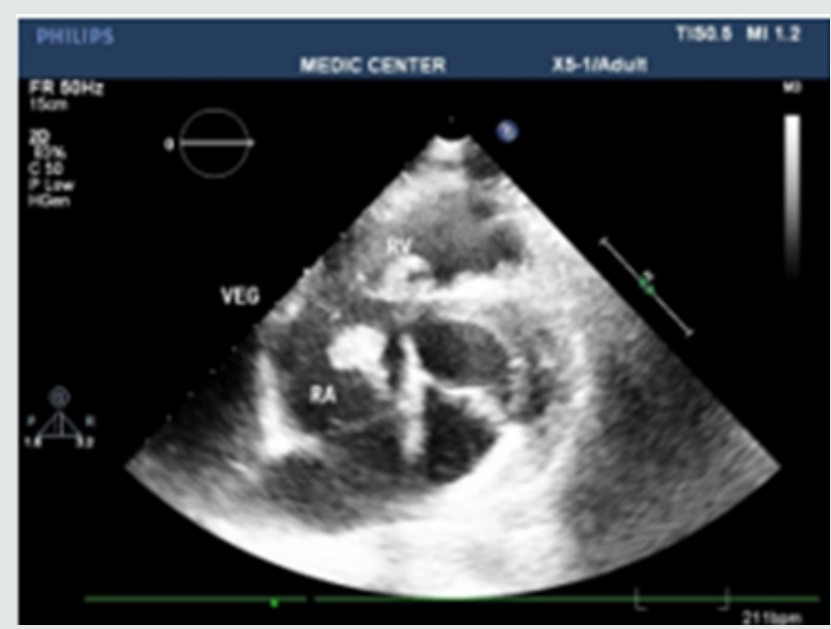

Figure 46: Vegetation seen at patient with VSD, 2DTEE imaging. 


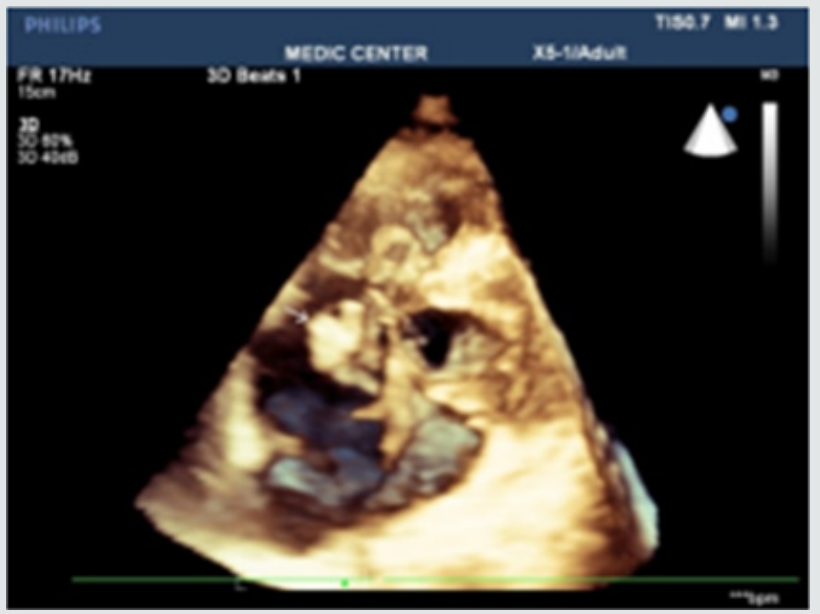

Figure 47: Vegetation seen at patient with VSD, Live 3DTEE imaging.

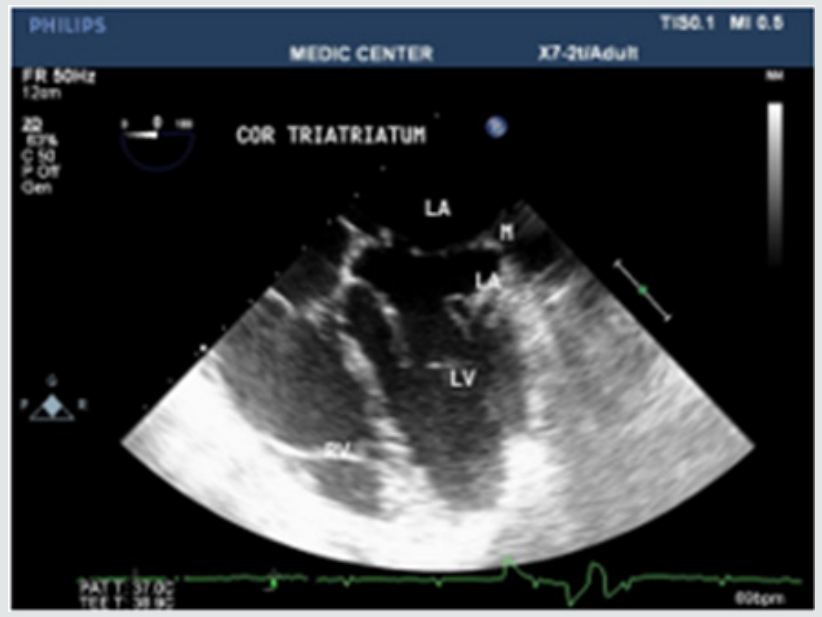

Figure 48: 2DTEE image with details of Cor Triatriatum.

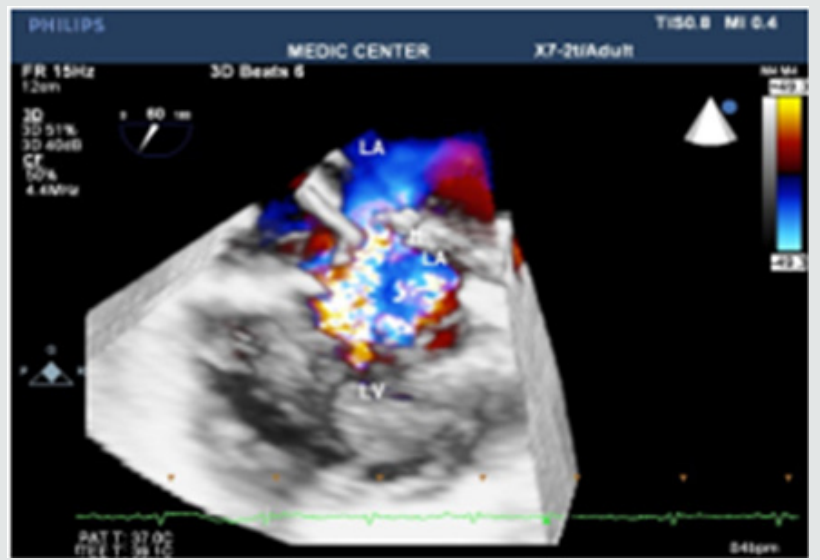

Figure 49: Cor Triatriatum with aliasing flow through the separated membrane.

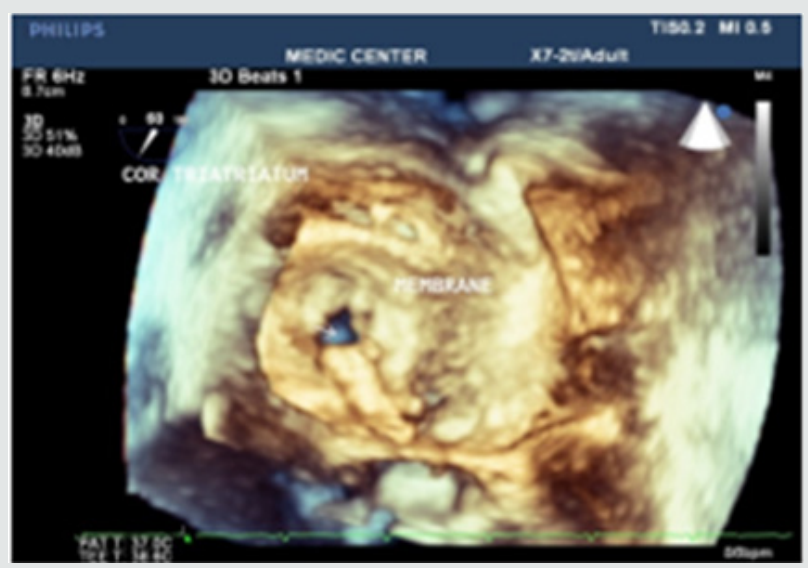

Figure 50: Cor Triatriatum viewed from LA: a small opening of membrane noted.

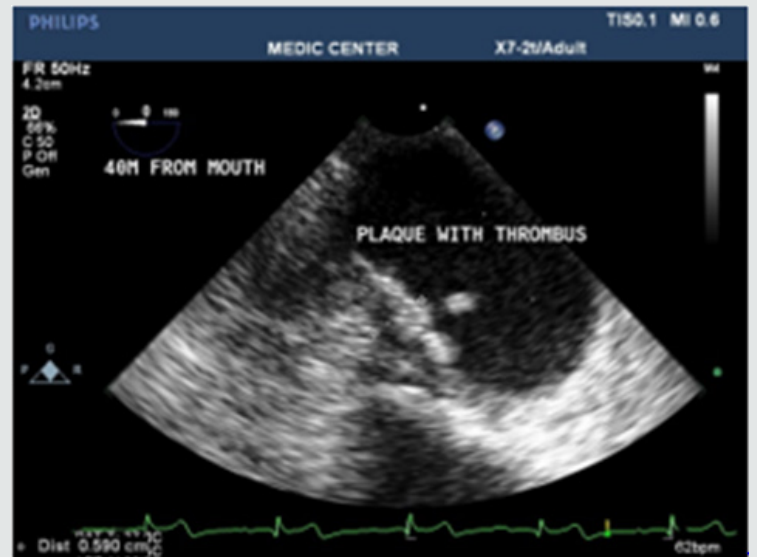

Figure 51: Atheromatous plaque of descending Aorta recorded on 2DTEE.

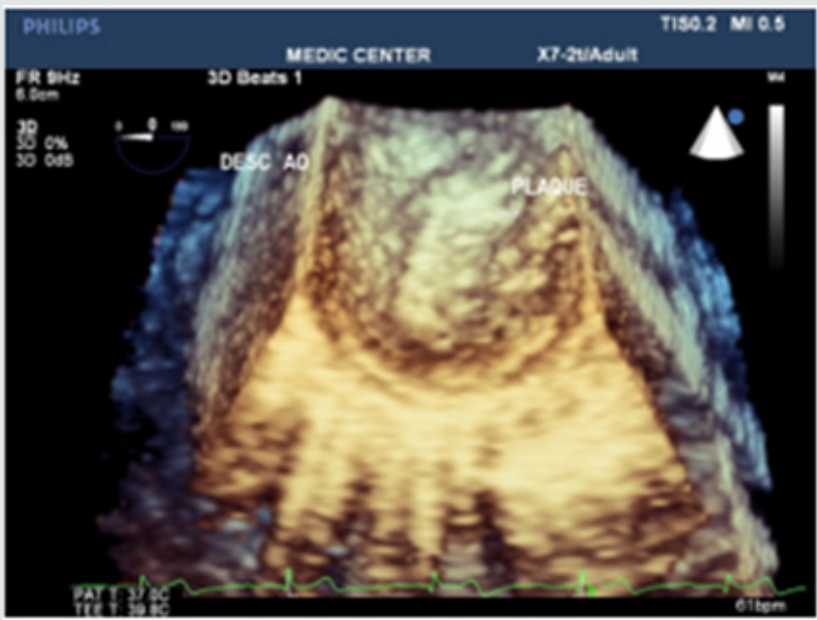

Figure 52: Atheromatous plaque of descending Aorta recorded on Live 3DTEE. 


\section{Discussion}

Three-Dimensional (3D) TEE is a novel technique that provides excellent images of the mitral valve to assess valve anatomy, evaluate the severity [15]. [6] studied 43 consecutive patients with rheumatic mitral stenosis and found that $\mathrm{MVA}^{3 \mathrm{D}}$ measurements were significantly lower compare with $\mathrm{MVA}^{2 \mathrm{D}}$ (mean difference $\left.-0.16 \pm 0.22 \mathrm{~cm}^{2}, \mathrm{p}<0,005\right)$. In our study we found $\mathrm{MVA}^{3 \mathrm{D}}$ significantly smaller mean $\mathrm{MVA}^{2 \mathrm{D}}$ : mean difference $=0,21 \mathrm{~cm}^{2}$ with $\mathrm{p}<0,001$. The cropping function on 3D TEE ensures that the orifice area is measured in a plane that is at the tip of the mitral valve and perpendicular to the inflow through the valve [12]. Assessment of consequences on the LA and LAA (study LA volume, LAA thrombi) using X-plan function and 3D Zoom should be preferred because it is accurate and strongly related to predicting thromboembolic events and detecting thrombi [15]. Thrombi in LA and LAA were recorded on 24 patients with $\mathrm{AF}$ and 4 patient with sinus rhythm in our study results. In the current area, Live 3D TEE is a useful complementary tool in assessing the size, site, and shape of an ASD, its rims and relations with neighboring structures. It is also helpful in confirming the good positioning of a device and identifying the site of any residual shunt next to device closure [11]. We always display a true and face view of the defect from the left atrium so that its dimensions can be accurately measured12. Three dimensional 3D TEE clearly visualizes the shape and the rims in a view only, that previously were obtained only by many consecutive 2D views. Review of 72 successful cases of ASD device closure demonstrates the size of ASD and its rims were always recorded and measured on the 3D TEE view from the left atrium. Three patients with unsuccessful ASD device closure related to short aortic rim (from 0 to $3 \mathrm{~mm}$ ). Case Endocarditis of pulmonary valve is very rare one, the rough systolis murmur at left sternal border resulted in a false diagnosis of disease as small VSD. Patient then had been sent to our department one year later to practice TTE and TEE because of fever. TTE, 2D TEE then 3D TEE consecutively was done. Vegetation of $11 \times 5 \mathrm{~mm}$ in size recorded from parasternal short axis view TTE and 2D TEE, then we found a mobile vegetation with greater size about $14 \times 7 \mathrm{~mm}$ associated with dilated pulmonary trunk of $35 \mathrm{~mm}$ in diameter and a subpulmonary valve aneurys $\mathrm{m}$ of $25 \mathrm{x} 36 \mathrm{~mm}$ MDCT-640 was indicated and detected a subpulmonary valve aneurysm of $27 \times 38 \mathrm{~mm}$ and pulmonary trunk dilatation of $40 \mathrm{~mm}$ in diameter.

Surgical plasty of pulmonary valve and aneurysmal resection were performed [4] Figure 53-56 reported a case of pulmonary valve vegetation, the patient was an old man 63 y.o, his past history included CAD status post bypass grafting with postoperative course complicated by an Enterococcus faecalis blood stream infection and aortic valve endocarditis. The Author did not explain why the vegetation attached to the pulmonary cusps from the left side as aortic valve endocarditis. [2] published an isolated pulmonic valve endocarditis case. The patient had no underlying valvular disease, he was later found to be bacteremia with $\mathrm{S}$ mitis. TEE detected a large pulmonic valve vegetation.

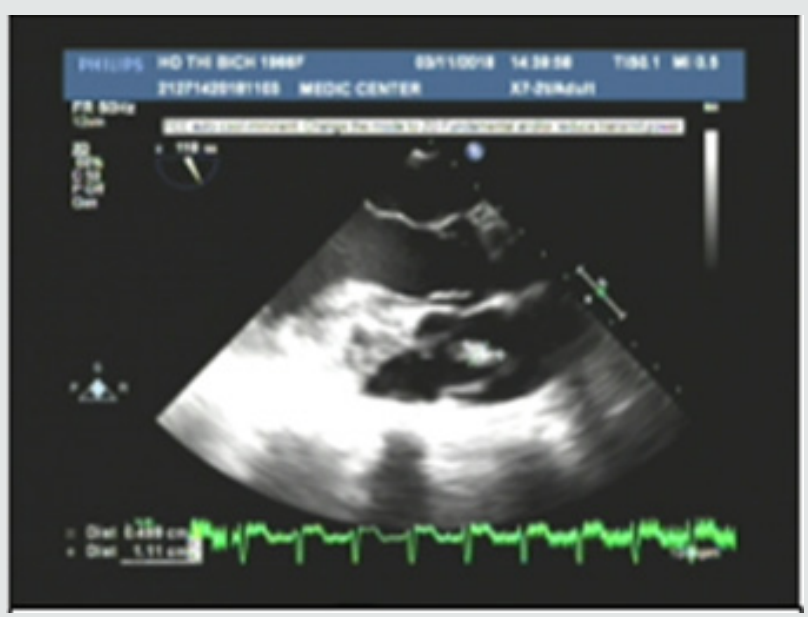

Figure 53: 2DTEE multiplane shows vegetation attached to pulmonary valve.

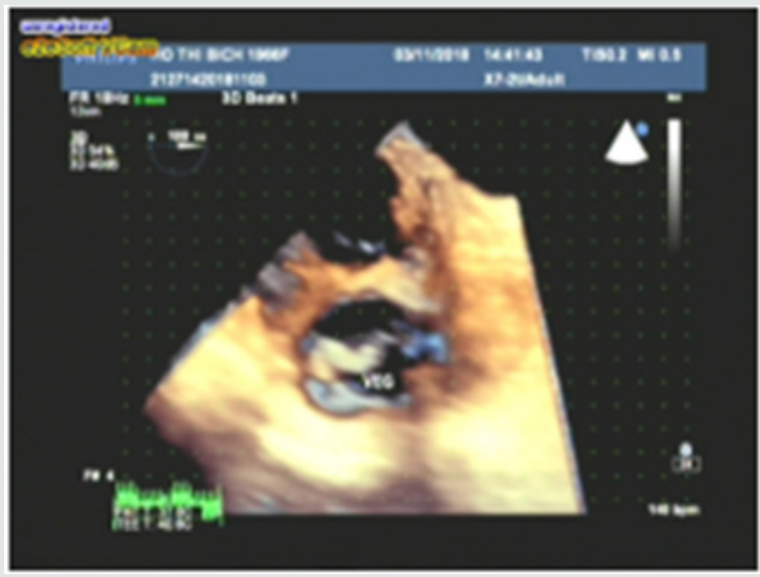

Figure 54: 3DTEE better showing the shape, size and mobility of vegetation.

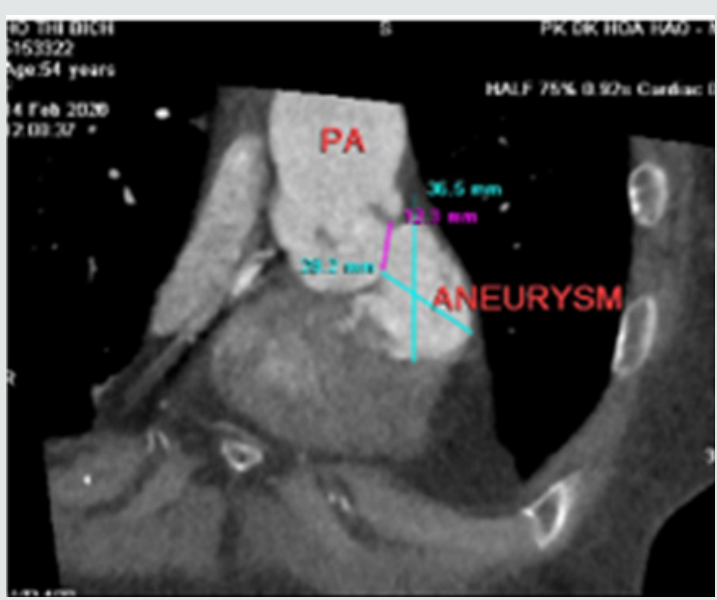

Figure 55: MDCT with MPR image visualizing a subpulmonary valve aneurysm. 


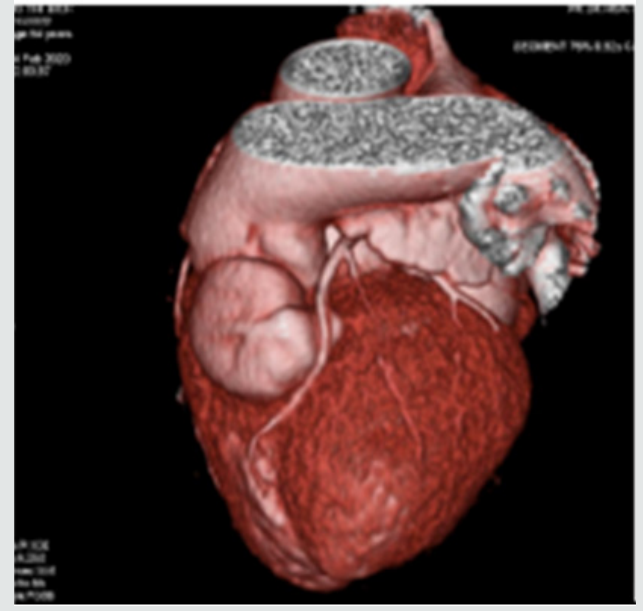

Figure 56:3D Surface Display image presents an aneurysm closed to infundibulum.

\section{Conclusion}

Most patients presented to be performed Three-Dimensional (3D) TEE were related to valvopathies, especially mitral stenosis; and congenital shunts in which atrial septal defects were predominant. Three Dimensional (3D) TEE ensures that the orifice area is measured in a plane that is at the tip of the mitral valve. Determination of the status of commissural fusion, particularly the symmetry length of commissural fusion is valuable information to predict the success of Balloon Mitral Commissurotomy. Three Dimensional (3D) TEE enables improved visualization of ASDs using unique and face representation of the interatrial septum. Three Dimensional (3D) TEE provides the valuable information's including shape, size of defect, its rims prior to perform transcatheter device closure. Three Dimensional (3D) TEE overcomes the disadvantages of other modalities like fluoroscopy, 2D TTE, 2D TEE during percutaneous interventions, for example 3D TEE is the unique modality can show the total anatomical structures in only one view.

\section{References}

1. C Blaeakley, M Eskandari, O Aldalati, K Moschonas, M Huang, et al (2018) Impact of 3D echocardiography on grading of mitral stenosis and prediction clinical events". Echoresearch and pratice 5(4): 105-111.

2. Jevon Samaroo Campbell, Arsalan Hashmi, Rajat Thawani, Manfred Moskovits, Dmitriy Zadushlivy et al. (2019) Isolated Pulmonic Valve Endocarditis. Am J Case Rep 20: 151-153.
3. Masaki Izumo, Maiko Shiota, Saibal Kar, Swaminatha V Gurudevan, Kirsten Tolstrup, et al. (2013) Comparison of Real-Time ThreeDimensional Transesophageal Echocardiography for Quantification of Mitral Valve Prolapse in Patients with Severe Mitral Regurgitation. Am J Cardiol 111(4): 588-594.

4. Melissa Lyle, Raul Espinosa (2018) Pulmonary Valve Endocarditis. JACC 71(11).

5. Ashok Kumar Omar, Vinay Sharma, Vivek Kumar, Arif Mustaqueem, Sameer Shrivastava (2019) Three-Dimensional Echo and Threedimensional Transesophageal Echocardiography for Mitral Valve Disease. Jour iaecho 3(3): 163-176.

6. Dominik Schlosshan, Gunjan Aggarwal, Gita Mathur, Roger Allan, Greg Cranney (2011) Real-Time 3D Transesophageal Echocardiography for the Evaluation of Rheumatic Mitral Stenosis. JACC: Cardiovascular Imaging 4(6): 580-588.

7. Vinay K Sharma, S Radhakrishnan, S Shrivastava (2011) Threedimensional trans-esophageal Echocardiographic Evaluation of Atrial Septal Defects: A Pictorial Essay. Images Pediatr Cardol 13(3): 1-18.

8. Frank E Silvestry, Meryl S Cohen, Laurie B Armsby, Nitin J Burkule, Craig E Fleishman, et al. (2015) Guidelines for the Echocardiographic Assessment of Atrial Septal Defect and Patent Foramen Ovale: From the American Society of Echocardiography and Society for Cardiac Angiography and Interventions". J am soc echocardiogr 28(8): 910-958.

9. William A Zoghbi, David Adams, Robert O Bonow, Maurice Enriquez Sarano, Elyse Foster (2017) Recommendations for Noninvasive Evaluation of Native Valvular Regurgitation. A report from the American Society of Echocardiography Developed in Collaboration with the Society of Cardiovascular Magnetic Resonance. Journal of the American Society of Echocardiography 30(4): 303-371.

10.William F Armstrong, Thomas Ryan (2010) Feigenbaum's Echocardiography. $7^{\text {th }}$ (edt.), William \& Wilkins p: 01-38.

11. Michael A Gatzoulis, Gary D Webb, Piers EF Daubenney (2018) Diagnosis and Management of Adult Congenital Heart Disease. $3^{\text {rd }}$ (edt.), Elsevier pp: 306-315.

12. Edward A Gill (2013) Atlas of 3D Echocardiography. $1^{\text {st }}$ (edt.), Elsevier pp: 75-338.

13. Roberto M Lang, Luigi P Badano, Wendy Tsang, David H Adams, Eustachio Agricola et al. (2012) EAE/ASE Recommendations for Image Acquisition and Display Using Three-Dimensional Echocardiography. JAm Soc Echocardiography 25(1): 3-46.

14. Gerald Maurer (1994) Transesophageal Echocardiography. McGraw-Hill pp: $1-65$.

15. Catherine Otto (2017) The Practice of Clinical Echocardiography. $5^{\text {th }}$ (edt), Elsevier pp: 261-455.

16. Raymond Roudaut (1994) EchocardiographieTransoesophagienne. Centre Hospitalier Universitaire Bordeaux.

17. Eric J Topol, Paul S Teirstein (2016) Textbook of Interventional Cardiology. $7^{\text {th }}$ (edt.), Elsevier pp: 727-811. 


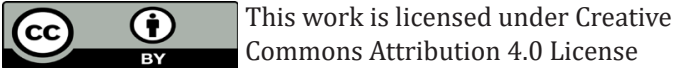

To Submit Your Article Click Here: Submit Article

DOI: 10.32474/ACR.2020.03.000152

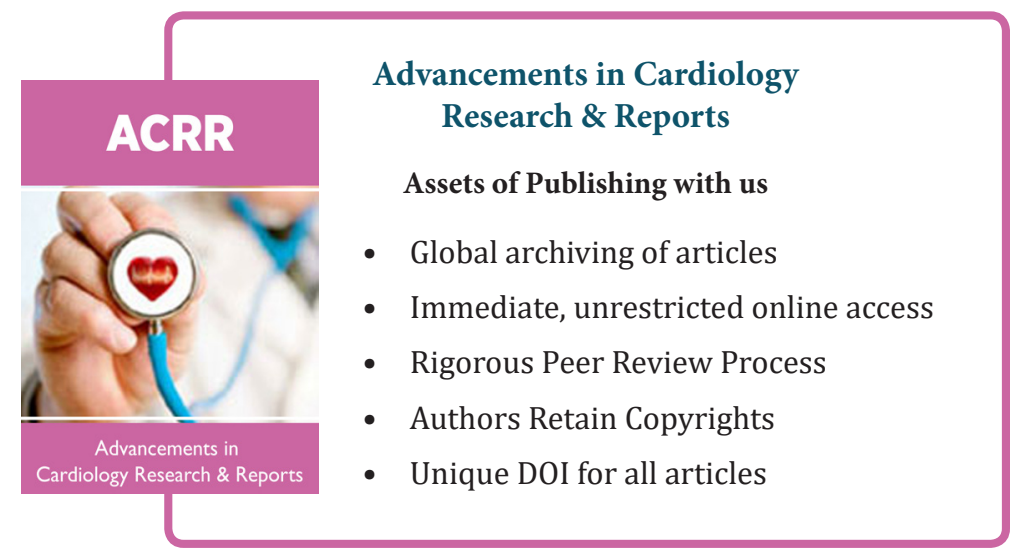

